\title{
Identifying the comprehensive pore structure characteristics of a rock from 3D images
}

\author{
Zhipeng Xu, Mian Lin \\ Institute of Mechanics, Chinese Academy of Sciences, Beijing, 100190, China \\ School of Engineering Science, University of Chinese Academy of Sciences, Beijing, 100049, China
}

\section{Wenbin Jiang}

Institute of Mechanics, Chinese Academy of Sciences, Beijing, 100190, China

\section{Gaohui Cao}

Institute of Mechanics, Chinese Academy of Sciences, Beijing, 100190, China

School of Engineering Science, University of Chinese Academy of Sciences, Beijing, 100049, China

\section{Zhixing Yi}

Institute of Mechanics, Chinese Academy of Sciences, Beijing, 100190, China

\section{A R T I C L E I N F O}

\section{Keywords}

Pore structure characterization

Geometric parameters

Topological parameters

X-ray CT image

Pore throat identification

\begin{abstract}
A B S T R A C T
Characterization of pore structure in reservoirs plays a significant role in predicting properties of rocks and classifying the reservoirs. The focus is on determining comprehensive geometric and topological parameters of pore structure. X-ray computerized tomography scanning provides a 3D image of the pore structure. However, these images cannot directly generate pore structure parameters without numerical characterization of the images. A new method is developed to determine comprehensive geometric and topological parameters of pore structure from images. These parameters were determined by utilizing common mathematical morphology operations to segment the entire pore space into a series of space blocks of different radii, subsequently identifying these blocks as pores and throats based on the proposed morphological features of pore and throat. The parallel scheme was also studied to obtain the highest efficiency. Thereafter, the characteristics of pore structures and the performance of the method were assessed for various samples. The results were compared to the results calculated by other methods. Results showed that the method produced reliable pore structure characteristics for a wide variety of rocks. Additionally, in order to discuss whether our results can be used as the basic input data for other researches, an example about two-phase flow simulation was made and a comparison of simulation results and experimental data was made. Our results were a competent choice for other studies. Also, after proposing the detection criteria of pore and throat, the subsequent detecting procedure is without artificial adjustable parameters, making the method convenient to use. This method can comprehensively, efficiently, accurately, and conveniently characterize the pore structure based only on images.
\end{abstract}

\section{Introduction}

The macro properties of reservoirs, such as porosity, permeability, and hydrocarbon content, are important for evaluating reservoir quality and identifying sweet spots (Clarkson et al., 2013; Xiao et al., 2017; Tahmasebi et al., 2017). A majority of the macroscopic properties of

\footnotetext{
* Corresponding author. Institute of Mechanics, Chinese Academy of Sciences, Beijing, 100190, China.

E-mail address: linmian@imech.ac.cn (M. Lin).
} 


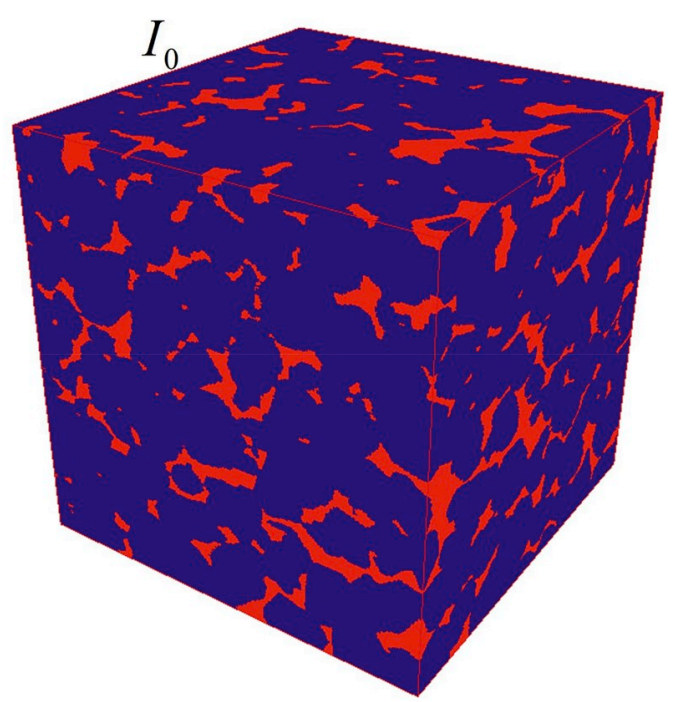

Fig. 1. A 3D binary image $I_{0}$ consists of pore space (red) and solid matrix (blue). (For interpretation of the references to color in this figure legend, the reader is referred to the Web version of this article.)

reservoirs are mainly controlled by microscopic physical properties of the pore structure (An et al., 2016; Daigle et al., 2017; Hu et al., 2017; Xiong et al., 2016; Fagbemi et al., 2018; Hollis et al., 2010). Therefore, the characterization of pore structure is important for predicting properties of rocks and evaluating and classifying reservoirs. The key is determining comprehensive geometric and topological parameters of the pore structure (Wu et al., 2019; Jiang et al., 2017). The geometric parameters include pore radius distribution, throat radius distribution, shape factor distribution of throat section, and the roughness of pore space wall. The topological parameters comprise of the number of pores and throats, coordination number distribution which characterizes local connectivity, Euler number which characterizes overall connectivity, and tortuosity.

Several experimental methods, comprising of the indirect measurement techniques on core plugs, have been used to characterize pore structure of porous media. For example, gas isothermal adsorption (GID) (Langmuir, 1918; Guo, 2013), mercury injection capillary pressure (MICP) (Okolo et al., 2015; Njiekak et al., 2018), and nuclear magnetic resonance (NMR) (Lai et al., 2018; Frosch et al., 2000; Yao et al., 2010) are some of the techniques. However, single experiment cannot obtain the comprehensive geometric and topological parameters, for example the MICP could only get the pore throat radius distribution and the GID could only obtain the general pore size distribution. Hence, several experiments and direct imaging techniques are often combined for comprehensive characterization of pore structure, which reduces convenience of use and increases costs.

With the progress in imaging technologies, the pore structure can now be directly characterized by X-ray computerized tomography scanning (Arns et al., 2005; Peng et al., 2012; Müter et al., 2012, 2014; Gooya et al., 2016), laser scanning confocal microscopy (Minsky, 1988; Kus, 2015) and various microscopy such as the optical microscopy, scanning electron microscopy (SEM) (Henares et al., 2014) and focused ion beam scanning electron microscopy (FIB-SEM) (Tomutsa et al., 2007). The obtained grayscale images can be two-dimensional (2D) and three-dimensional (3D). 2D images, such as the SEM image, can describe more details of pore structure in high resolution, but cannot characterize the realistic geometric and topological properties of the 3D pore structure. The characterization of pore structure is often based on 3D images.
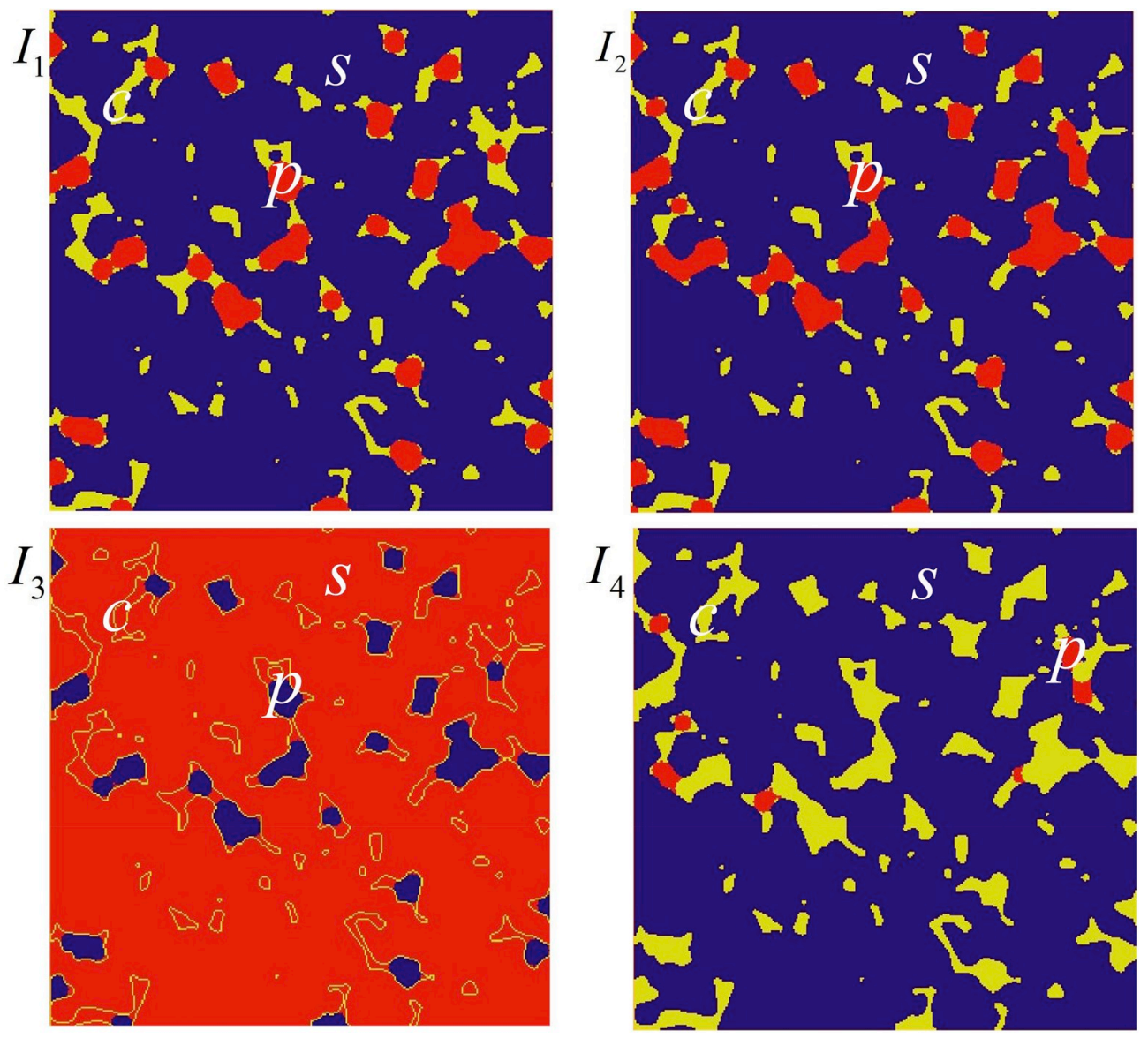

Fig. 2. The image $I_{1}$ and $I_{2}$ are transformed from the image $I_{0}$ by a structure element of radius $R$ and $R-1$, respectively. The image $I_{3}$ is obtained by exchanging the values of void voxels and solid voxels in $I_{1}$. The image $I_{4}$ is obtained by $I_{4}=I_{2} \& I_{3}$, and it consists of solid matrix (blue), space blocks of radius $R$ (red), and pore spaces which have been transformed into solid matrix (yellow). $s, p$, and $c$ denote solid voxel, void voxel, and void voxel which had been converted to solid voxel, respectively. (For interpretation of the references to color in this figure legend, the reader is referred to the Web version of this article.) 


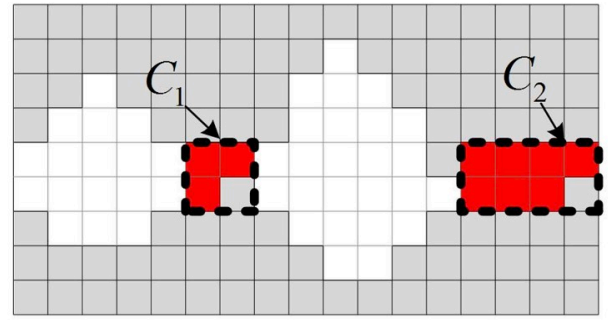

(a)

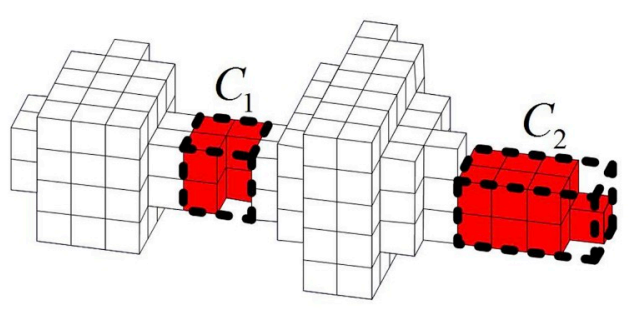

(b)

\begin{tabular}{|c|c|c|c|c|c|c|c|c|c|c|c|c|c|c|c|c|c|c|c|}
\hline \begin{tabular}{l|l}
0 & 0 \\
\end{tabular} & \begin{tabular}{l|l}
0 & 0 \\
\end{tabular} & \begin{tabular}{l|l}
1 & 1 \\
\end{tabular} & \begin{tabular}{l|l}
1 & 1
\end{tabular} & \begin{tabular}{|l|l|}
0 & 0 \\
\end{tabular} & \begin{tabular}{l|l}
0 & 0 \\
\end{tabular} & \begin{tabular}{|l|l|}
0 \\
\end{tabular} & 0 & 0 & 0 & 0 & \begin{tabular}{|l|l|l|}
0 & 0 \\
\end{tabular} & \begin{tabular}{l|l}
0 & 0
\end{tabular} & \begin{tabular}{|l|l|}
0 & 1 \\
\end{tabular} & 0 & \begin{tabular}{l|l}
0 & 0
\end{tabular} & 0 & 0 & \begin{tabular}{l|l}
0 & 0 \\
\end{tabular} & 0 \\
\hline \begin{tabular}{|l|l|}
0 & 0 \\
\end{tabular} & \begin{tabular}{l|l|}
0 & 0 \\
\end{tabular} & \begin{tabular}{|l|l}
1 & 1 \\
\end{tabular} & \begin{tabular}{|l|l}
1 & 1 \\
\end{tabular} & \begin{tabular}{|l|l|}
0 & 0 \\
\end{tabular} & \begin{tabular}{l|l}
0 & 0 \\
\end{tabular} & 0 & 0 & 0 & 0 & 0 & \begin{tabular}{|l|l|l}
0 & 0 \\
\end{tabular} & \begin{tabular}{|l|l|}
0 & 0
\end{tabular} & \begin{tabular}{|l|l|}
0 & 1 \\
\end{tabular} & & \begin{tabular}{l|l}
0 & 0 \\
\end{tabular} & \begin{tabular}{|l|l|}
0 \\
\end{tabular} & & \begin{tabular}{l|l}
0 & 0 \\
\end{tabular} & 0 \\
\hline $\mathrm{N}$ & $\mathrm{S}$ & W & $\mathrm{E}$ & $\mathrm{U}$ & $\mathrm{D}$ & & $\mathrm{N}$ & & & & $\mathrm{S}$ & & W & & $\mathrm{U}$ & & & $\mathrm{D}$ & \\
\hline
\end{tabular}

(c)

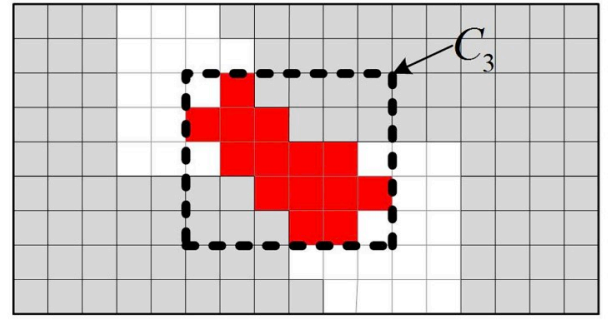

(d)

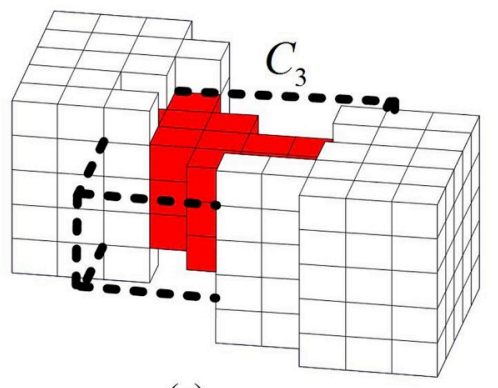

(e)
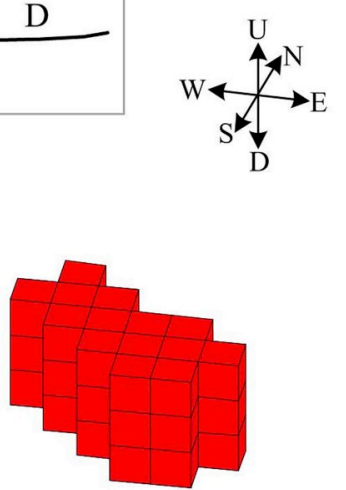

(f)

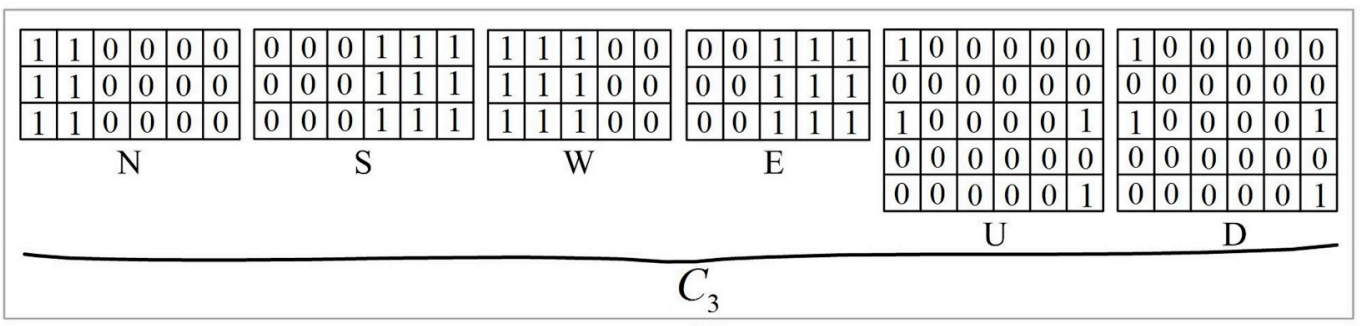

(g)

\section{Legend: $\square$ 2D Solid Voxel $\quad$ 2D Connected Block \\ 2D Void Voxel in the Connected Block \\ 3D Connected Block \\ 3D Void Voxel in the Connected Block \\ $\square$ 2D Void Voxel outside the Connected Block $\square$ 3D Void Voxel outside the Connected Block}

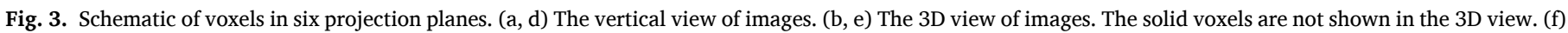

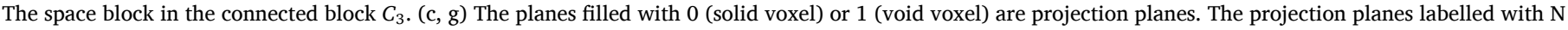

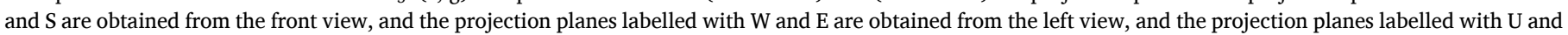
$\mathrm{D}$ are obtained from the vertical view.

However, only few pore structure characteristics can be acquired by simple and intuitive observation of grayscale images. By the segmentation algorithm on 3D grayscale images, it is possible to easily convert the images to the binary images, where each element has a value of either 0 (solid voxel) or 1 (void voxel) (Müter et al., 2012; Salzer et al., 2014). The developed pore structure characterization algorithm can extract pore structure parameters from the 3D binary images (Hilpert and Miller, 2001; Lindquist and Venkatarangan, 1999; Silin et al., 2003).

So far, only a few numerical pore structure characterization approaches have been based on 3D binary images, such as the pore network method (Lindquist and Lee, 1996; Dong and Blunt, 2009; Yi et al., 2017), the fuzzy logic method (Moaddel et al., 2018) and the mathematical morphology method (Hilpert and Miller, 2001; 2003; Yang et al., 2015; Sweijen et al., 2017). The mathematical morphology method is a common and powerful method for image processing that has been used widely for characterizing the pore structure from images. The method, which is based on the mathematical morphology concept founded by Matheron (1975) and Serra (1982), transforms several complex image processing steps into combinations of translation and logical operations, such as dilation, erosion, opening and closing. Through erosion and dilation operations on pore space by a structuring element of radius $r$, the pore spaces whose radii are less than or equal to $r$ are converted into solid matrix. $r$ increases from the minimum radius of pore space to the maximum radius of pore space and eventually, the morphological and geometric properties of the entire pore space can be obtained. Hilpert and Miller (2001) used the approach to obtain the capillary pressure-water saturation curve in a porous media. Sweijen et al. (2017) and Yang et al. (2015) extracted the capillary pressure-saturation curve and acquired the pore size distribution in a porous media. Compared with other characterization approaches based 


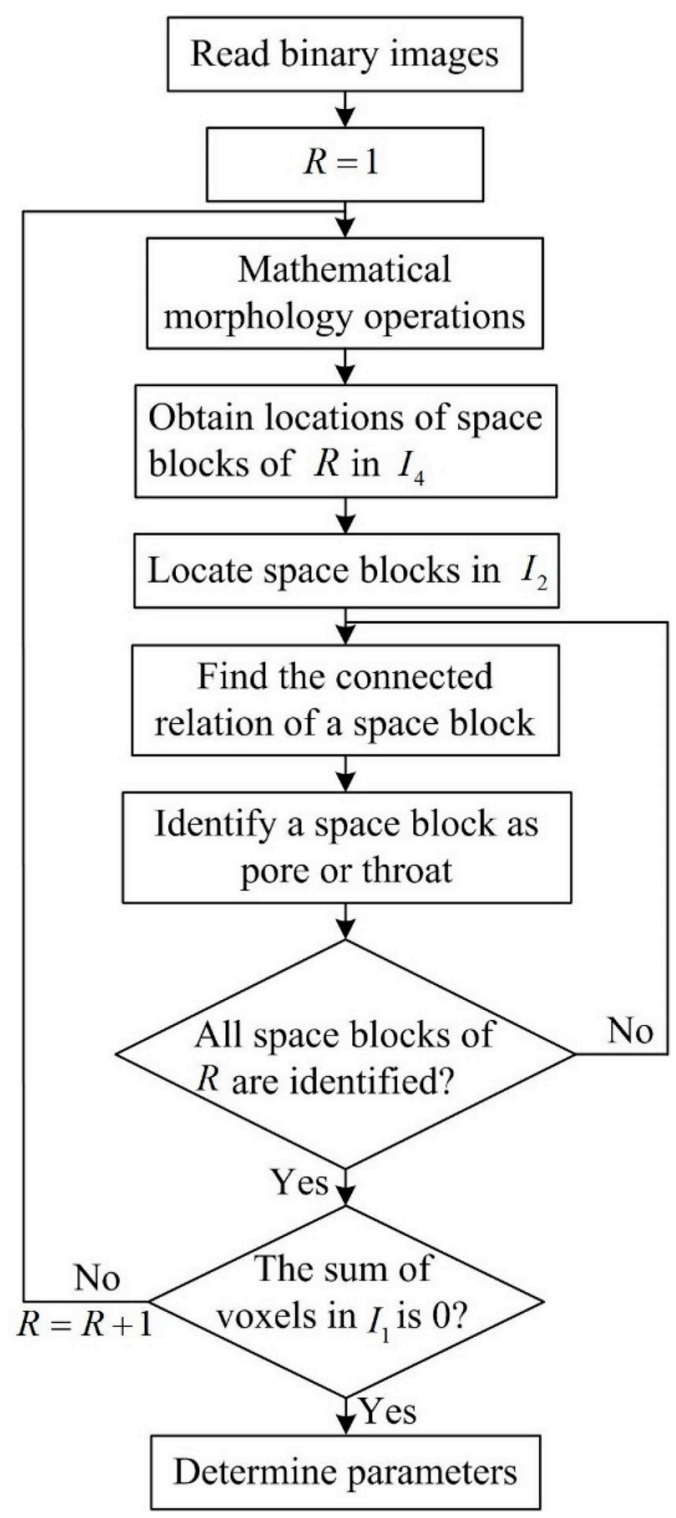

Fig. 4. Workflow of the PTM method. on images, the mathematical morphology method is simple and intuitive, and characterizes the pore structure based only on the actual morphology of pore space. Hence, there are no simplifications of pore space. However, since the approach cannot identify pore space as pores and throats, the topological parameters of pore structure cannot be determined.

A morphology algorithm, named pore throat morphology (denoted by PTM) algorithm, was developed in this study in order to determine comprehensive geometric and topological parameters of the pore structure. Pores and throats were directly separated and identified by combining the common mathematical morphology method with the proposed morphological features of pore and throat. The rest of this paper is organized as follows. In section 2, the principles, main steps, parallel scheme, and computational efficiency of the PTM algorithm are described. In section 3 , the characteristics of pore structures and the performance of the method for various samples, the comparison of PTM results and the results calculated by other methods, and the usability of PTM results for other studies are discussed. Finally, the summary of this study is drawn in Section 4. Twelve samples including 10 sandstones and 2 carbonates were used in this study. The samples were shared by Imperial College London (Dong and Blunt, 2009). The sample properties were outlined in Appendix A Table A1.

\section{Methodology}

Although the mathematical morphology method is a powerful tool for image processing, it cannot directly identify pore space as pores and throats for determination of geometric and topological parameters. A full-morphology algorithm was developed based on the mathematical morphology method to separate and detect pores and throats from a 3D binary image $I_{0}$ (see Fig. 1). The major idea of the PTM algorithm is as follows: the entire pore space is first segmented into a series of space blocks of different radii via the mathematical morphology method, the morphological features of pore and throat are proposed, and the obtained space blocks are identified as pores and throats based on the proposed morphological features.

\subsection{Obtainment of space blocks}

In our algorithm, obtaining space blocks of different radii from the entire pore space was the basis of identifying pores and throats. In order to provide a better understanding of the acquisition process, we used a 2D slice of $I_{0}$ to illustrate it (Fig. 2). First, the entire pore space was

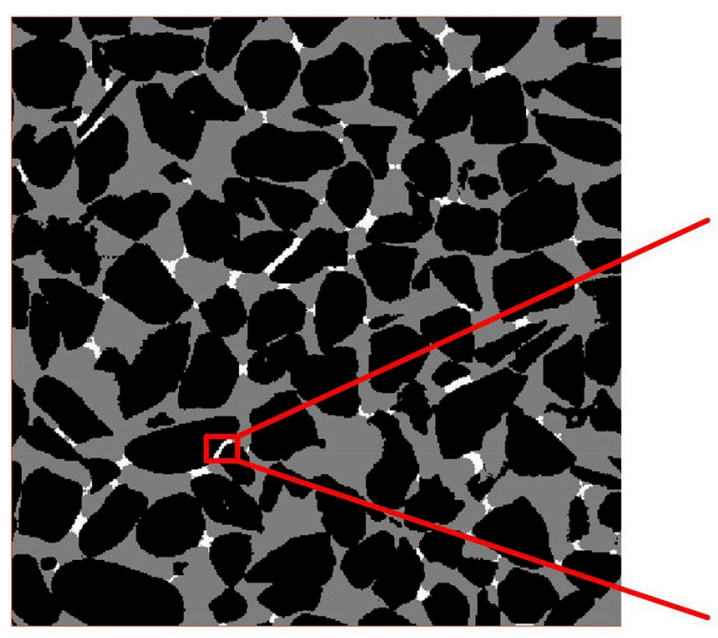

(a)

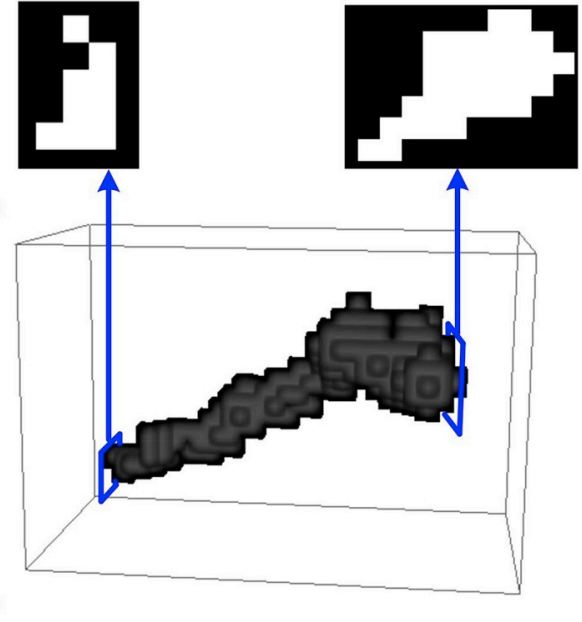

(b)

Fig. 5. (a) Pores (gray color), throats (white color), and solid matrix (black color) in an image slice. (b) The 3D morphology, inlet cross section, and outlet cross section of one throat. (For interpretation of the references to color in this figure legend, the reader is referred to the Web version of this article.) 


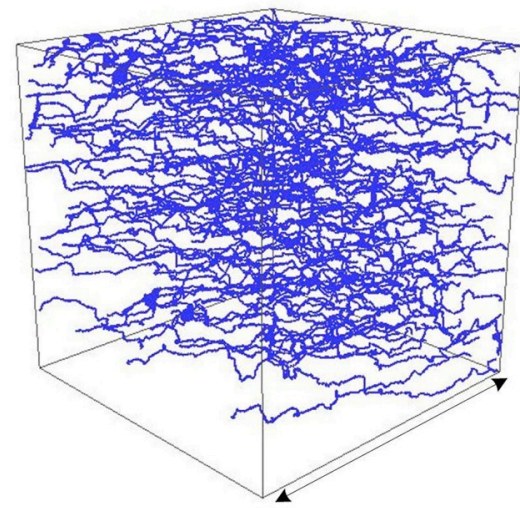

(a)

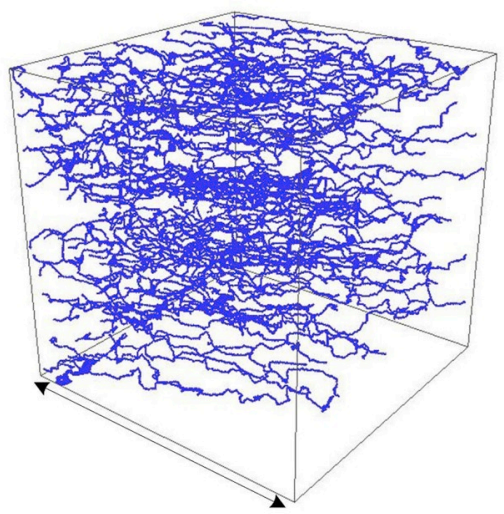

(b)

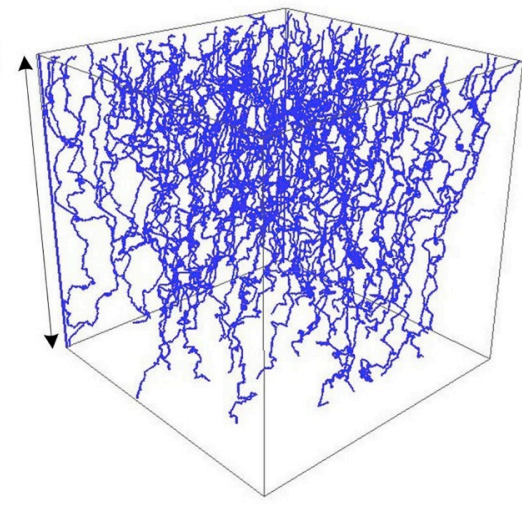

(c)

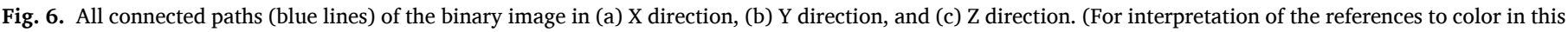
figure legend, the reader is referred to the Web version of this article.)

eroded and dilated by a structuring element, whose radius was defined as $R$, and the pore spaces whose radii were less than or equal to $R$ were converted into solid matrix. For more details about the structuring element and operations of erosion and dilation, one can refer to the textbooks of Matheron (1975) and Serra (1982), and the work of Hilpert and Miller (2001) and Yang et al. (2015). The $I_{0}$ was transformed into the image $I_{1} . I_{1}$ consisted of three types of voxels: solid voxel $s$, void voxel $p$, and void voxel $c$, which had been converted into a solid voxel (see Fig. $2 I_{1}$ ). Thereafter, the identical operations were conducted on $I_{0}$ by a structuring element of $R-1$ to obtain the image $I_{2}$, which contained pore spaces of radius larger than or equal to $R$ (Fig. $2 I_{2}$ ). Afterward, the values of void voxels and solid voxels in $I_{1}$ were exchanged to generate the image $I_{3}$ (see Fig. $2 I_{3}$ ). The logical AND operation was conducted between $I_{2}$ and $I_{3}$ to get the image $I_{4}\left(I_{4}=I_{2} \& I_{3}\right)$, which contained space blocks of $R$ (see Fig. $2 I_{4}$ ). Note that $I_{2}$ is $I_{0}$, if $R=1$.

Since space blocks of $R$ are obtained by the morphological operations, the boundaries of space blocks were unique. These space blocks were subsequently identified as pores and throats in a way that the boundary between pore and throat was unique.

\subsection{Identification of pore and throat}

After space blocks of $R$ were obtained, these were identified as pores or throats based on the morphological features of pore and throat. The first step was determining the morphological features of pore and throat. The pore space in porous media can be represented by a system in the form of pores (the larger spaces) connected by throats (the long and narrow spaces). The morphological features of throat are summarized as follows. Both ends of the throat must connect two spaces whose radii are larger than the throat radius. A space block was defined as a throat, if it satisfied the above-mentioned morphological features, else it was defined as a pore.

The voxels in projection planes were used to judge whether both ends of a space block connected two larger spaces. The projection planes correspond to six surfaces of the space block. The detailed process is shown below.

(1) Defining a space block of $R$ as pore or throat depends on whether both ends connect two spaces of radii larger than $R$. Since $I_{4}$ had space blocks of $R$ only, the connected relations could not be found in it. $I_{2}$ contained pore spaces of radii larger than or equal to $R$, so we first obtained locations of each space block in $I_{4}$ and individually located them in $I_{2}$ to find the connections. The location scheme was described as follows. The connectivity analysis based on 6-adjacencies was first performed on space blocks in $I_{4}$, and the connected blocks were generated. Each connected block was a regular cuboid, containing a space block and few surrounding solid voxels (see connected blocks $C_{1}, C_{2}$, and $C_{3}$ in Fig. 3). Therefore, each space block of $R$ could be located by vertex coordinates and side lengths of the corresponding connected block.

(2) Finding the connections for the six surfaces of the connected block in $I_{2}$. The surfaces were classified into six types: $\mathrm{N}$ (north), $\mathrm{S}$ (south), W (west), E (east), U (up), and D (down), as shown in Fig. 3. Each surface corresponded to a projection plane, whose distance to the surface was 1 (voxel unit), and was located in the external normal direction of the surface. The cases of voxels in projection planes are as follows.

a If there were only solid voxels in a projection plane, the corresponding surface of space block was considered as a pore space wall or the interface with a space of radius less than $R$, which had been converted into solid matrix. Therefore, the space block did not connect a space of radius larger than $R$ to the corresponding surface (see Fig. 3, projection planes of N, S, $\mathrm{U}$, and D surfaces in $C_{1}$ and $C_{2}$ ).

$\mathrm{b}$ If there were only void voxels in a projection plane, the corresponding surface of space block was the interface with a space of radius larger than $R$. Since there were no spaces of radii less than $R$ in $I_{2}$, and the space block could not connect spaces of $R$ after the connectivity analysis, the space block could only connect a larger space by the corresponding surface (see Fig. 3, projection planes of $\mathrm{W}$ and $\mathrm{E}$ surfaces in $C_{1}$ ).

c If the projection plane contained both solid voxels and void voxels, three possible cases could exist, as discussed below. First, the corresponding surface of space block would probably be the interface with a space of radius larger than $R$. However, the radius of another interface in the larger space would be less than $R$ (see Fig. 3, projection plane of W surface in $C_{2}$ ). In order to further determine this possibility, new projection planes were obtained along the external normal direction of the surface to determine the voxels cases. If there were new projection planes, which contained only void voxels, the space block connected to a larger space by the corresponding surface. Otherwise, the voxels cases in six projection planes were analyzed at the same time. If there were both solid voxels and void voxels in each projection plane, the space block connected more than one space of radii larger than $R$ to different surfaces (see Fig. 3, six projection planes of surfaces in $C_{3}$ ). Finally, if the voxels case in the projection plane was different from the two cases mentioned above, the space block did not connect a space of radius larger than $R$ to the corresponding surface.

$\mathrm{d}$ If a projection plane was absent for the surface, the surface could be on the image boundary, and the space block was a 


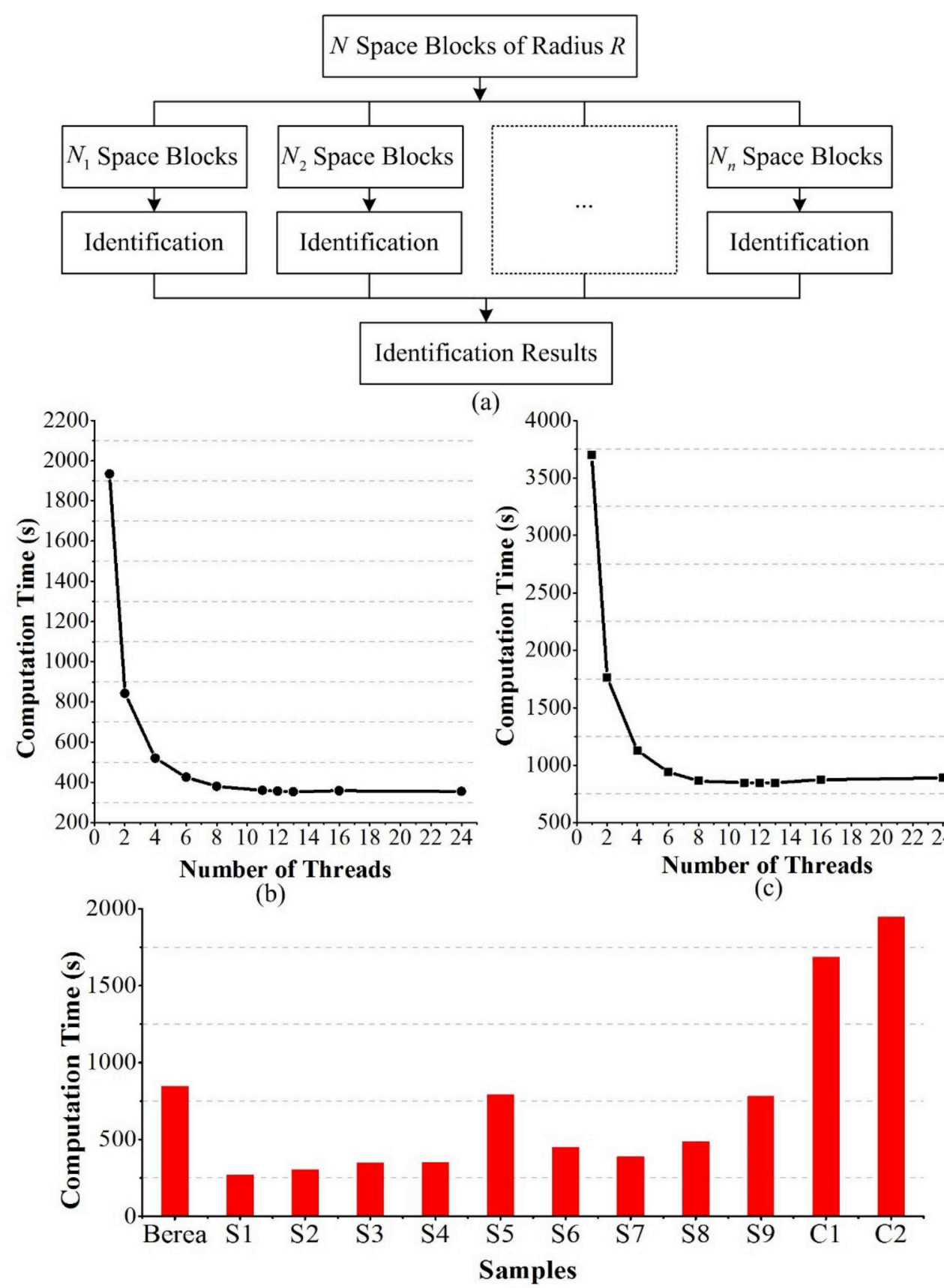

(d)

Fig. 7. (a) $N$ space blocks of $R$ are identified in parallel. (b, c) The relationship between computation time and the number of threads for $300^{3}$ voxels and $400^{3}$ voxels, respectively. (d) The computation time of 12 rock samples.

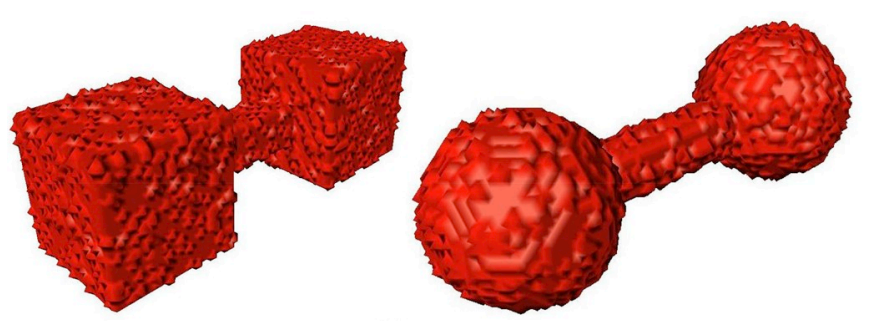

(a)

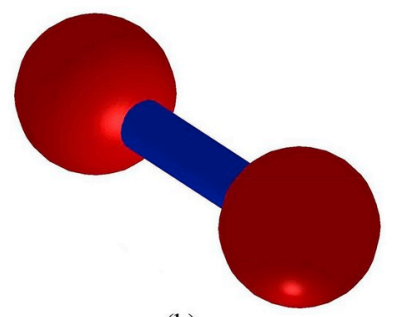

(b)

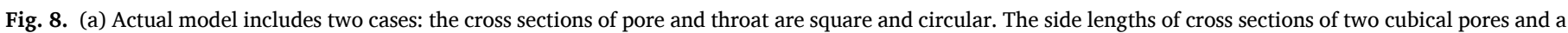

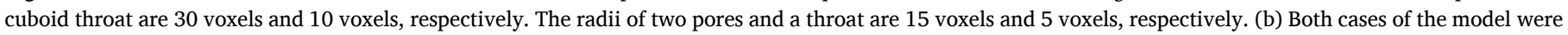
successfully identified as two pores connected by a throat. The radii of two pores and a throat were estimated as 15 voxels and 5 voxels, respectively. 


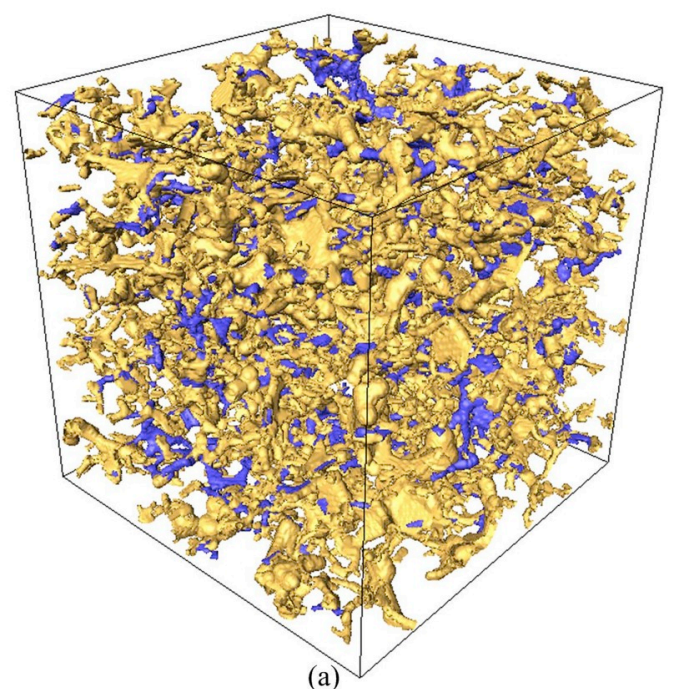

(a)
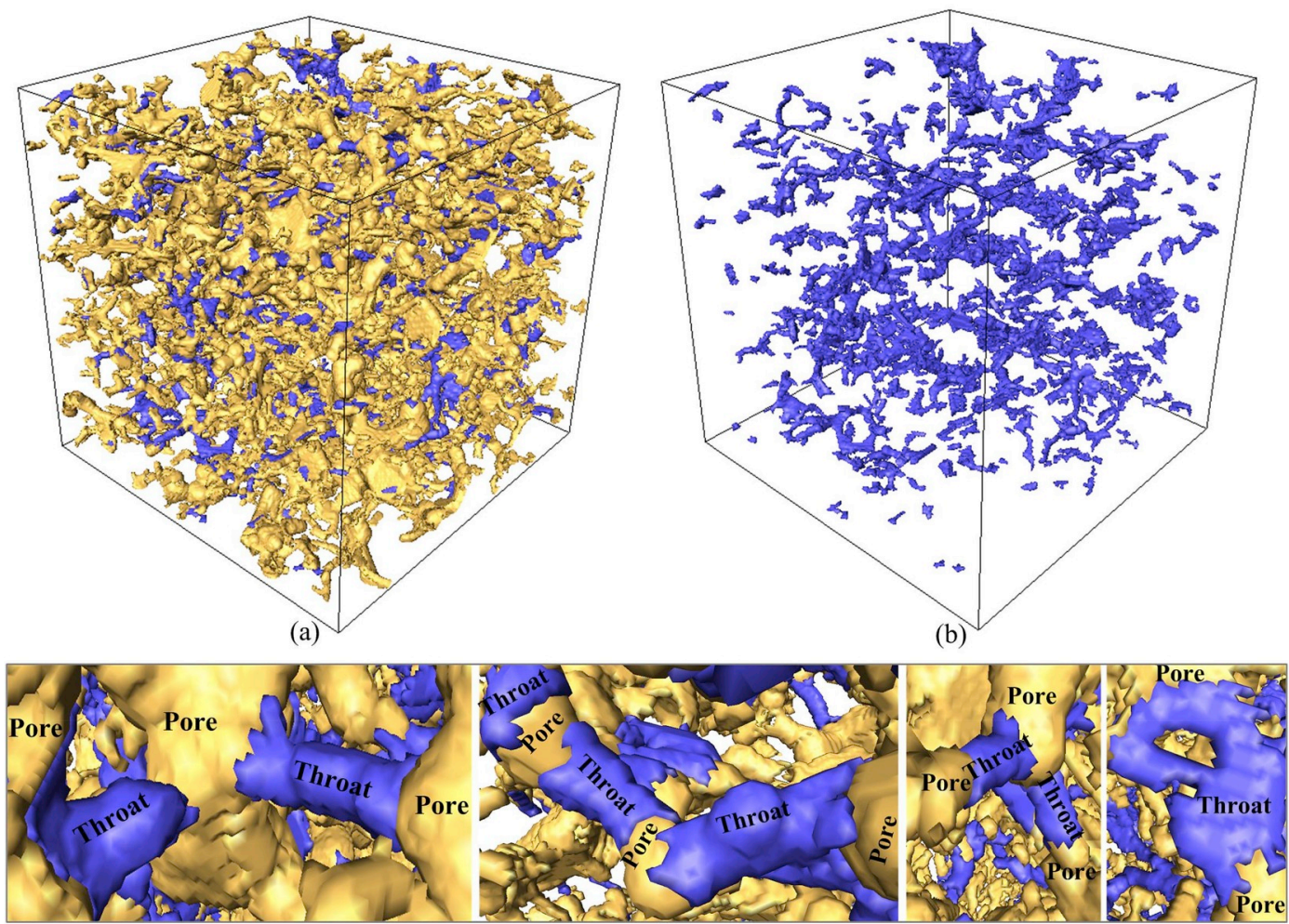

(c)

Fig. 9. The visualized identification results of a binary image S1. (a) The spatial distribution and the location relationship of pores and throats. (b) The spatial distribution and real shape of throats. (c) Some details of pores and throats connections.

boundary block (see Fig. 3, E surface in $C_{2}$ ). Since throat should not exist in the image boundary, the space block was defined as a boundary pore.

(3) Identifying a space block as pore or throat. If two surfaces of a space block interfaced with two spaces of radii larger than $R$, the space block was defined as throat (see Fig. 3, space block in $C_{1}$ ). The two surfaces cannot be adjacent, and there were no more than two surfaces connecting larger spaces, otherwise the space block would not be generated in the morphological operations. Moreover, the space block was also identified as throat, if its six projection planes contain both solid voxels and void voxels (see Fig. 3, space block in $C_{3}$ ). There were no spaces of radii less than $R$ in $I_{2}$, the space block would not be generated in morphological operations if it connected more than two larger spaces or the connected two larger spaces were adjacent. Also, if the space block was found to be a boundary block, it was defined as a boundary pore (see Fig. 3, space block in $C_{2}$ ). Apart from the above three cases, all other space blocks were defined as pore.

(4) Repeating the processes (2) and (3), until all space blocks of $R$ were identified as pores and throats.

Fig. 4 provides the entire workflow of the PTM method. Starting from $R=1$, space blocks of $R$ were obtained and individually identified them as pores or throats. When the entire pore space was converted into solid matrix (the sum of voxels in $I_{1}$ was 0 ), $R$ reached the maximum radius and all space blocks of different radii were identified as either pores or throats.

\subsection{Determination of parameters}

The last step was determining geometric and topological parameters of pore structure from the identified pore-throat system. The number of pores and throats were directly counted from the identified results. The coordination number of each pore from the pore-throat system was obtained and the coordination number distribution was arrived at using statistical method. The Euler number was calculated as the difference between pore number and throat number (Vogel and Roth, 2001). The radii of pores and throats were equal to the radii of the corresponding space blocks. The volume was determined by counting the number of voxels in the pore block and the throat block. In the end, all pore volume-radius results and throat volume-radius results were used to create the pore radius distribution and throat radius distribution, respectively.

The shape factor was calculated by the inlet and outlet interfaces of throat. In our algorithm, the inlet and outlet boundaries of the throat were clear, hence the throat interfaces were used to obtain the approximate cross section. In the pore-throat system, all voxels in each throat block were labelled by the serial number of the throat. Subsequently, the voxels cases in six projection planes of each pore block were determined. If a certain projection plane contained voxels labelled by a serial number of one throat, the corresponding surface in the throat was the interface between the pore and the throat (see Fig. 5), and the interface was taken as an approximate cross section of the throat. The intrinsic normal cross section could be inexistent in the discretized spaces constituted of voxels (Jiang et al., 2007). Besides, the interface is certain for the throat. The shape factor of the cross section was calculated using $G=A / P^{2}$ (Mason and Morrow, 1991), where $G$ is the shape factor, and $A$ and $P$ are the area and perimeter of the cross section, respectively. In the end, the average value of the inlet interface shape factor and the outlet interface factor was taken as the throat shape factor. The statistical results of throat number-shape factor created the shape factor distribution of throats.

The tortuosity (geometric tortuosity) and roughness have often been investigated directly on the entire pore space (Al-Raoush and Madhoun, 2017). Hence, the two parameters were calculated directly based on the morphology of the entire pore space. The tortuosity was calculated via 

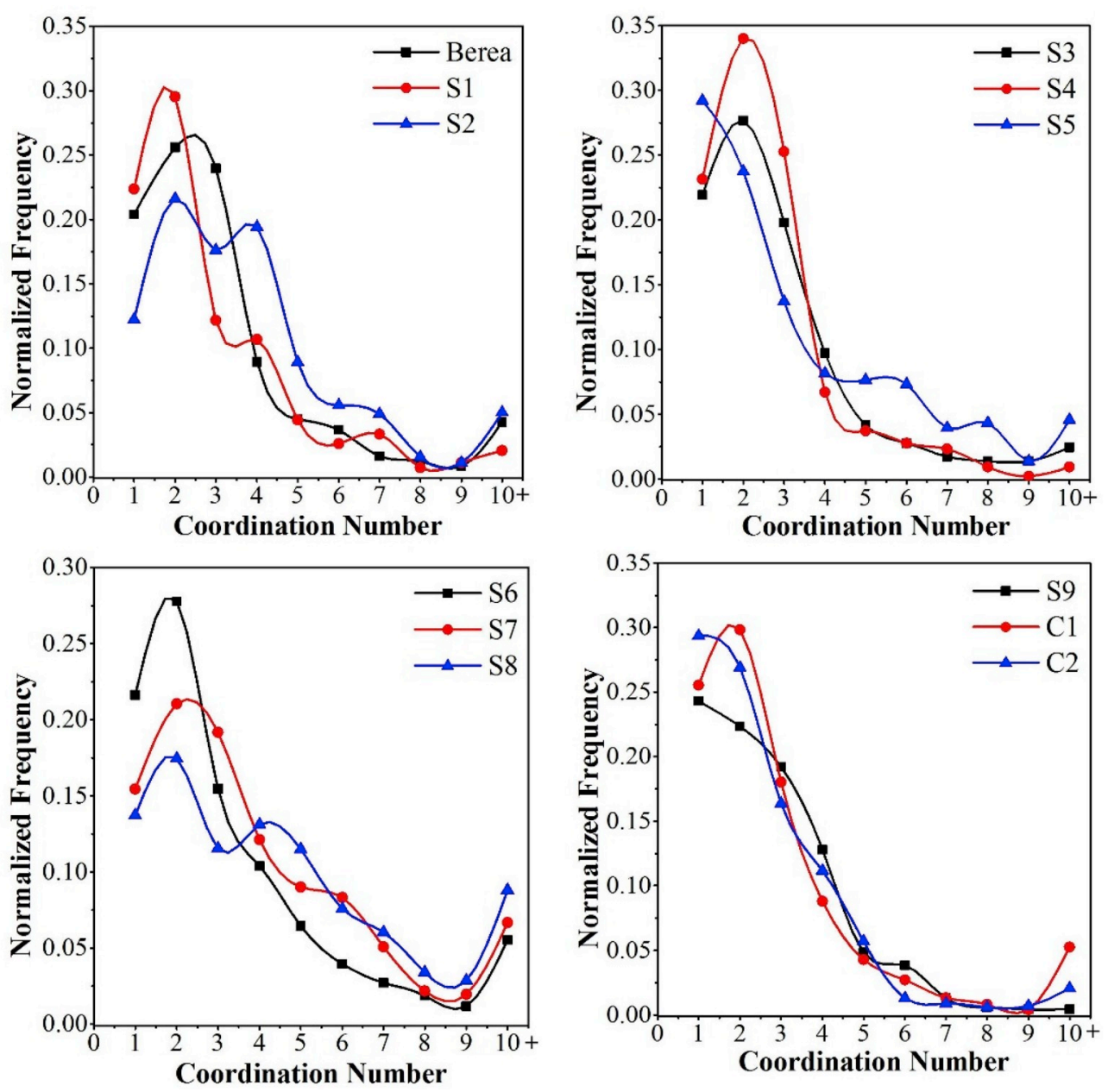

Fig. 10. Coordination number distributions of the samples studied.

the medial axis as follows. For each of the directions, the medial axis was built for each image slice that was perpendicular to this direction, and the origins in one boundary slice were identified via the intersections of the medial axis in the boundary slice. Finally, starting from one origin, guided searches were performed, and the next voxel of the connected path was identified in the next image slice medial axis based on 6-adjacencies. After all image slices in the direction were identified, a single connected path starting at one origin was obtained. The guided searches were repeated for other origins. Once all connected paths were generated (see Fig. 6), the tortuosity was calculated by $\tau_{d}=\left(\sum_{i=1}^{n} l_{i} / n\right) / l_{s}$, where $\tau_{d}$ is the tortuosity in the direction $d, d=1,2,3, n$ is the number of connected paths, $l_{i}$ is the length of the connected path $i$, and $l_{s}$ is the length of the straight path. The average tortuosity $\tau$ was computed by $\tau=\left(\tau_{x}+\tau_{y}+\tau_{z}\right) / 3$. For more details, refer to Al-Raoush and Madhoun (2017).

The roughness of pore space wall was calculated by the geometric roughness factor $f$, which is defined as the ratio of the actual area of a rough surface to its apparent area (Wenzel, 1936; Quéré, 2008). The calculation of $f$ for pore space wall is described as follows. First, the entire pore space wall was extracted via the mathematical morphology operations, and the resulting image consisted only of pore space wall and solid matrix. Thereafter, the image was divided into $m \times m \times m$ cubes, with the side length of each cube denoted by $w$. The $f$ of pore space wall in a cube is the ratio of the actual area of this wall to $w^{2}$, and the average value of $f \mathrm{~s}$ in all cubes was taken as the geometric roughness factor of the entire pore space wall. This scheme is similar to the differential box-counting approach (Sarkar and Chaudhuri, 1994). The $w$ was set to be 2 (voxel unit) to get the maximum probability of one surface of a cube being parallel to the pore space wall in the cube.

\subsection{Discussion of computational efficiency}

The entire pore space may be segmented into tens of thousands of space blocks, resulting in individually defining pores and throats a timeconsuming process. The PTM algorithm was found to be suitable for parallel computing. In each iteration, after $N$ space blocks of $R$ were obtained, these could be identified in parallel, and each thread processed $N_{i}$ blocks (see Fig. 7a). The parallel design was easy to implement since the identification course of each space block was independent of each other.

In order to test the optimal number of threads, two cases of $300^{3}$ voxels and $400^{3}$ voxels were calculated, and the number of threads used for testing was $1,2,4,6,8,11,12,13,16$, and 24 . It was found that when the number of threads was less than 11 , the computation time decreased significantly with an increase in the number of threads. However, when the number of threads continued to increase, the computation time increased at a slower rate with an increase in the number of threads (see Fig. 7b and c). In this study, the optimal number of threads was set as 11 . Fig. $7 \mathrm{~d}$ shows the computation time of 12 rock samples (see Table A1 in Appendix A). The minimum and maximum computation times were 271.65 s and 1945.15 s, respectively. Note that the computation time of S5, S9, C1, and C2 rock samples was relatively higher than that of other samples, but their number of pores and throats (see Table A2 in Appendix A) were not the highest. This could be due to the fact that their porosities are larger, which leads to more number of times of actual executed morphological operations. Considering the full- 

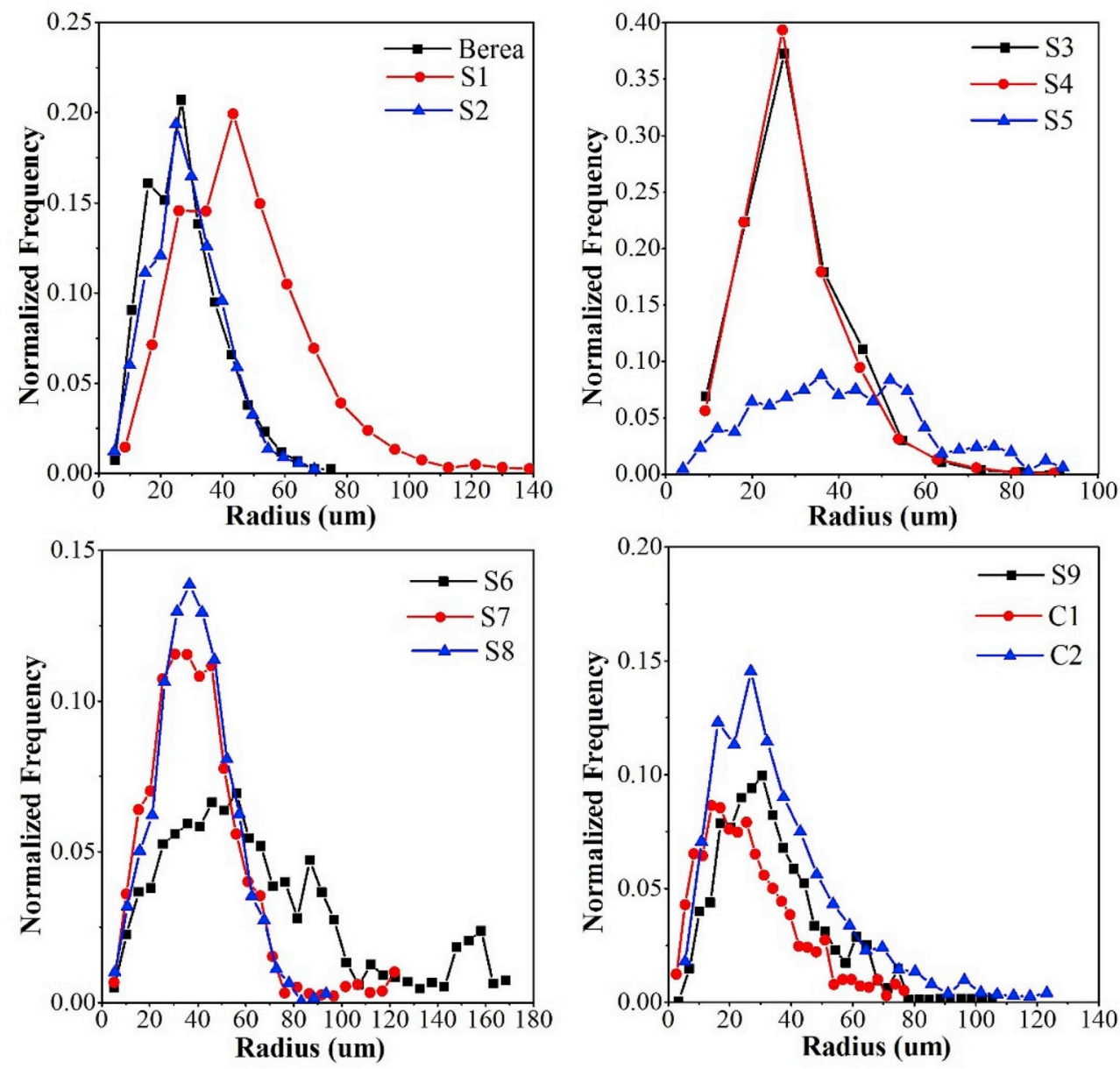

Fig. 11. Pore radius distributions of the samples studied.

morphology property of the proposed algorithm, the computational efficiency will be higher, if the GPU parallel techniques are implemented in the future.

\section{Results and discussion}

\subsection{Characterization of pore structure}

In order to assess the performance of the developed method in pore structure characterization, we first used a simple model of two pores connected by a throat (Fig. 8a). The model included two cases: the cross sections of pore and throat were square and circular. The irregular protrusions were added to the surface of pore and throat for more realistic. As shown in Fig. 8b, both cases of the model were successfully identified as two pores connected by a throat, and their sizes were given an acceptable estimate. In addition, since the limitation of the morphological operations (Matheron, 1975; Serra, 1982), some discrete voxels were inevitably produced, which were removed in our method. For the studied 12 samples using our method, the average ratio of the volume of removed voxels to the volume of identified pores and throats was 0.017 , which was much little. So the influence of removing discrete voxels on the results was acceptable.

Fig. 9 shows the visualized identification results of the binary image S1 (Fig. 1). As can be seen, each throat connected to two pores and every pore was connected to one or more throats. In addition, the pore number $N_{p}$, throat number $N_{t}$ and the average coordination number $C N_{\text {avg }}$ were 1787, 2637 and 2.95, respectively, which satisfied the formula: $C N_{a v g}=$ $2 N_{t} / N_{p}$. It indicates that the method only identifies space block connected to two larger spaces (pores) as throat.
The detailed results of the 10 sandstones and 2 carbonates have been discussed from two aspects: the analysis of properties of a single rock sample and of a group of rock samples. The obtained topological parameters that include the number of pores and throats, the average coordination number, the Euler number and tortuosity are listed in Table A2, and the coordination number distributions are shown in Fig. 10. The geometric parameters of average pore radius, the average throat radius and the geometric roughness factor are also listed in Table A2, and the pore radius distributions and the throat radius distributions are shown in Fig. 11 and Fig. 12, respectively. The results did not include the isolated pore spaces, which had been converted into solid matrix prior to the calculation.

For property analysis of a single rock sample, for example, the Berea sandstone, revealed that the $N_{p}, N_{t}$ and $C N_{\text {avg }}$ were 6055, 10166 and 3.37 (Table A2), respectively, which are considered high for sandstones. The Eu was -4133 (Table A2), which is little for sandstones. According to the significances of $C N_{\text {avg }}$ and $E u$, it concluded that the overall connectivity and local connectivity of pore structure are good. The values of $\tau$ and $f$ were 1.47 and 1.18 (Table A2), respectively, implying that the spatial distributions of pore structure are less intricate. Moreover, the $R_{p, a v g}$ and $R_{t, a v g}$ were found to be $16.40 \mu \mathrm{m}$ and $10.10 \mu \mathrm{m}$ (Table A2), respectively, which are low for sandstones, implying that the pore structure could be less developed. From Figs. 11 and 12, it can be seen that the maximum pore radius and throat radius were $74.83 \mu \mathrm{m}$ and $64.14 \mu \mathrm{m}$, respectively, implying that there was little difference in sizes of all pores and throats and the pore structure is homogenous. From the above analysis, it can be concluded that the developed method can comprehensively describe the pore structure properties of a rock sample solely based on the 3D image. 

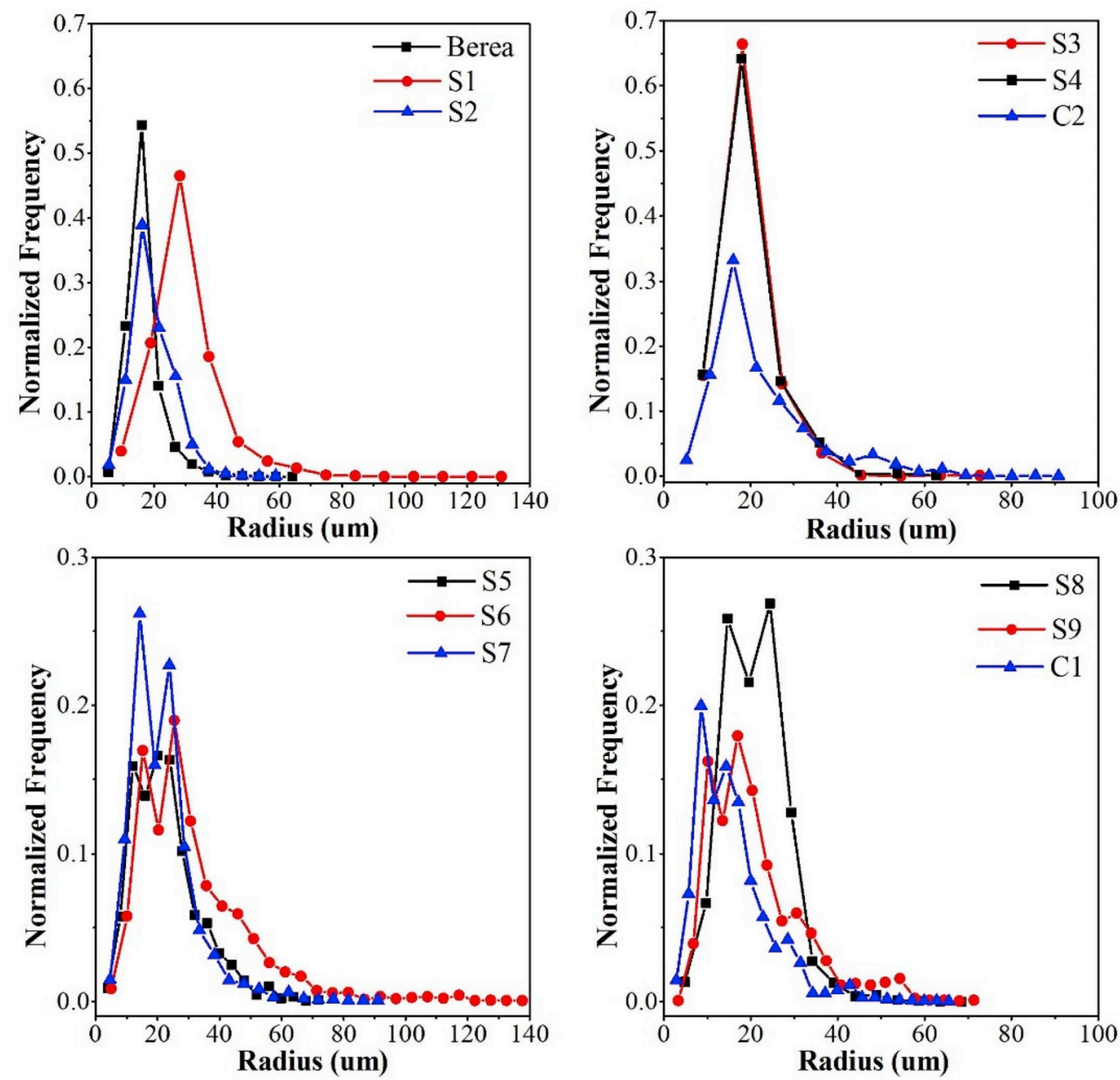

Fig. 12. Throat radius distributions of the samples studied.

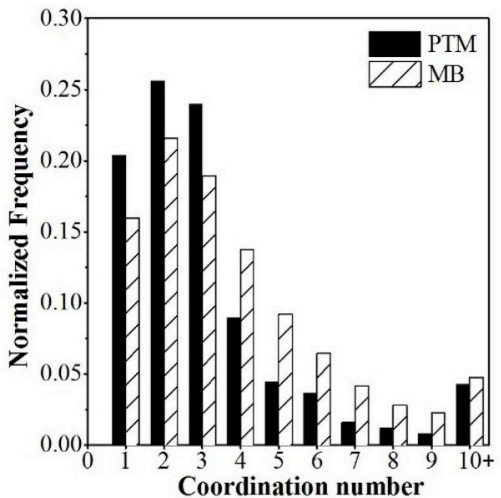

(a)

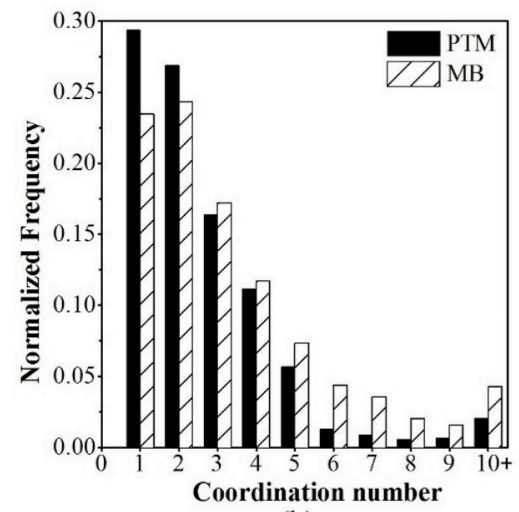

(b)

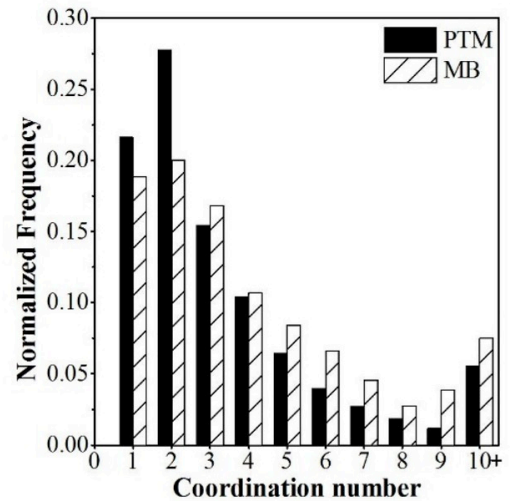

(c)

Fig. 13. Coordination number distributions of the PTM method and the MB method (Dong and Blunt, 2009) for (a) Berea, (b) C2 and (c) S6 samples.

As shown in Fig. 10, the analysis of properties of a group of rock samples showed that the coordination numbers of all the samples exceeded 10 , and their main coordination numbers were $1-4$. The S8 sandstone had the largest average coordination number of 4.45 (see Table A2) and the largest pore content fraction of large coordination number (see Fig. 10). From Table A2, it can be seen that the tortuosity values of all the samples ranged between 1.27 and 1.97, and the tortuosity values of S3, S4, C1, and C2 were larger than those of other samples. Moreover, the roughness factors of all the samples ranged between 1.11 and 1.29, and S3, S4, C1, and C2 samples also had larger roughness factors as compared to other samples. The tortuosity and roughness factor resulted in the absolute permeabilities of the four samples being less than those of other samples (Dong and Blunt, 2009; Yi et al., 2017). From Figs. 11 and 12, it can be seen that the $S 6$ sandstone had the largest pore and throat, with radii values of $168.3 \mu \mathrm{m}$ and $137.7 \mu \mathrm{m}$, respectively. Also, the average pore radius and the average throat radius of S6 and S1 sandstones were larger than those of other samples (see Table A2). This indicates that the pore structures of S6 and S1 sandstones are more developed. From the above analysis, it can be concluded that the method developed in this study can comprehensively describe 


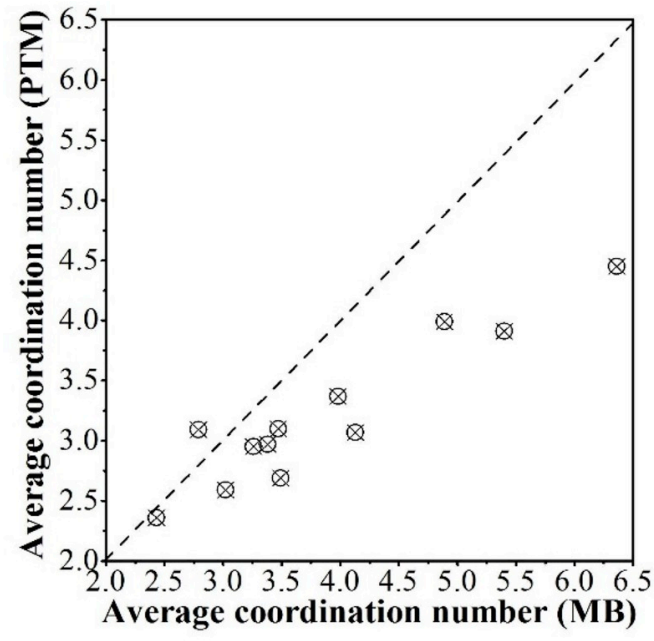

Fig. 14. Average coordination number of the PTM method versus average coordination number of the MB method (Dong and Blunt, 2009). The dashed line represents $\mathrm{y}=\mathrm{x}$ line.

the pore structure properties of a group of rock samples, which can be used to classify the pore structures and evaluate reservoirs.

As can be seen from Table A2, $N_{p}, N_{t}$, and $C N_{\text {avg }}$ for all samples satisfy the formula: $C N_{a v g}=2 N_{t} / N_{p}$, implying that PTM method only identifies space block connected to two larger spaces (pores) as throat, and ensures that each throat connects to two pores.

\subsection{Comparison of PTM and available methods}

The coordination number distributions of the PTM method were compared with those of the maximal ball (MB) method (Dong and Blunt, 2009) in Fig. 13. It can be observed from Fig. 11 that the S6 sandstone had the most non-homogeneous pore space. Moreover, the Berea sandstone was a benchmarking sample for the study of rocks because of its well-sorted and homogeneous properties (Alyafei et al., 2015; Raeini et al., 2014). Therefore, the comparison was implemented on S6, Berea sandstone, and C2 carbonate. From Fig. 13, the coordination number distributions of PTM were similar to those of MB, except that the MB results had more pores with higher coordination numbers, which resulted in higher average coordination number of the MB results. The average coordination numbers of PTM versus those of MB were plotted in Fig. 14.

As shown in Fig. 14, the average coordination number of the MB method was generally larger than that of the PTM method. Moaddel et al. (2018) compared the fuzzy logic method with the MB method and found that the MB method tends to calculate larger average coordination number. In addition, these average coordination numbers of the PTM results ranged between 2.5 and 4.5, which were in agreement with other average coordination numbers calculated by the fuzzy logic method for sandstones and dolomites.

We compared the pore and throat radius distributions of the PTM method to the results calculated by the MB method for Berea, S6 and C2 samples (Fig. 15). Good agreement between throat radius distributions of PTM and MB for 3 samples was obtained. The MB method found more pores with larger pore radius than the PTM method, but the MB results had less pore content fraction than the PTM results when the pore radius was smaller. The phenomenon was consistent with the above observation of connectivity that excess large pores connected with more satellite pores, which were caused by image noise, resulting in larger average coordination number of MB.

Since the throat volume content was little (For the studied 12 samples, the average ratio of throat volume of PTM and MB to the entire pore space volume was $13.13 \%$ and $14.11 \%$, respectively.), the total volume of pores was close to that of the entire pore space, and the peak radius $R_{p}$ of pore radius distribution was close to that of the entire pore space size distribution. $R_{p}$ refers to the radius corresponding to the peak of each distribution. In order to investigate which pore radius

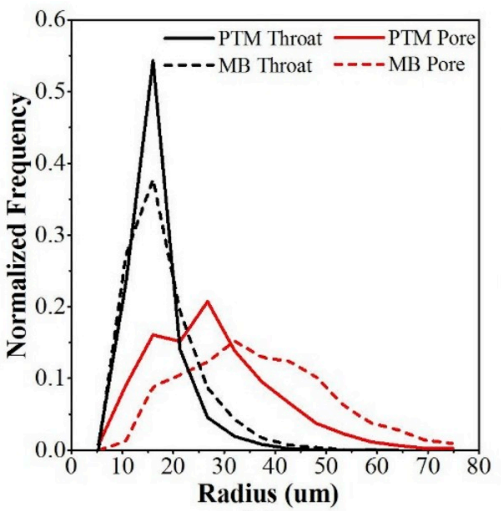

(a)

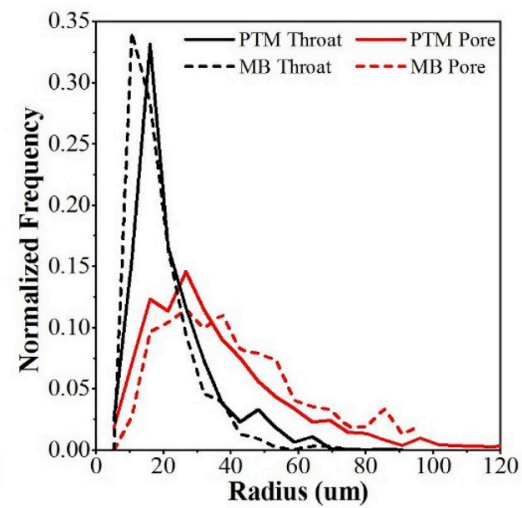

(b)

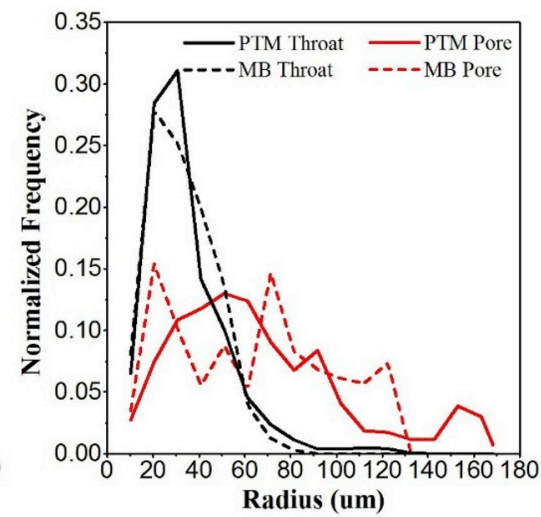

(c)

Fig. 15. Pore and throat radius distributions of the PTM method and the MB method (Dong and Blunt, 2009) for (a) Berea, (b) C2 and (c) S6 samples.

Table 1

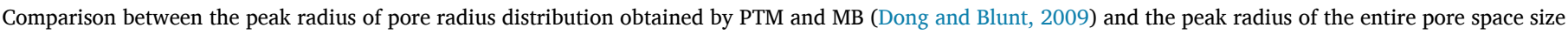
distribution obtained by erosion and dilation operations (Matheron, 1975; Serra, 1982).

\begin{tabular}{|c|c|c|c|c|c|c|c|c|c|c|c|c|}
\hline Sample & Berea & S1 & $\mathrm{S} 2$ & S3 & S4 & S5 & S6 & S7 & S8 & S9 & $\mathrm{C} 1$ & $\mathrm{C} 2$ \\
\hline$R_{p}($ erosion $)[u m]$ & 16.04 & 43.42 & 24.78 & 27.30 & 26.88 & 35.97 & 25.50 & 24.02 & 24.46 & 30.58 & 14.25 & 16.04 \\
\hline$R_{p}(M B)[u m]$ & 32.07 & 69.46 & 29.74 & 36.40 & 35.84 & 63.95 & 15.30 & 52.83 & 44.03 & 47.57 & 8.55 & 26.73 \\
\hline$R_{p}(P T M)[u m]$ & 26.73 & 43.42 & 24.78 & 27.30 & 26.88 & 35.97 & 56.10 & 28.82 & 34.24 & 30.58 & 14.25 & 26.73 \\
\hline$R E(M B)$ & 1.00 & 0.60 & 0.20 & 0.33 & 0.33 & 0.78 & 0.40 & 1.20 & 0.80 & 0.56 & 0.40 & 0.67 \\
\hline$R E(P T M)$ & 0.67 & 0.00 & 0.00 & 0.00 & 0.00 & 0.00 & 1.20 & 0.20 & 0.40 & 0.00 & 0.00 & 0.67 \\
\hline
\end{tabular}

$R_{p}$ and $R E$ are the peak radius and absolute relative error. 


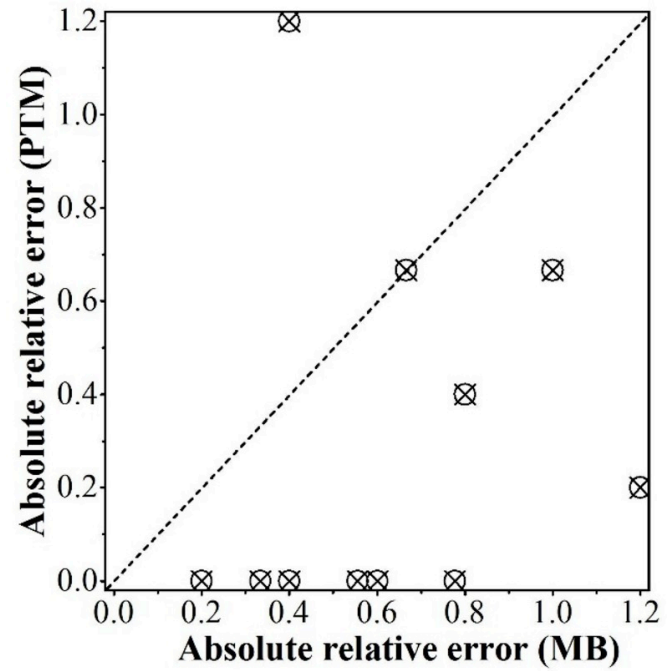

Fig. 16. Absolute relative error of PTM result versus absolute relative error of MB result (Dong and Blunt, 2009). Error was calculated with respect to the peak radius of the entire pore space size distribution. The dashed line represents $\mathrm{y}=$ $\mathrm{x}$ line. distribution of MB and PTM was more likely, we compared their $R_{p}$ to that of the entire pore space size distribution (See Table 1). The entire pore space size distribution was obtained by two morphological operations: the erosion of solid matrix and the dilation of pore space (Matheron, 1975; Serra, 1982).

As shown in Table $1, R_{p}$ s from the MB pore radius distributions were farther away from $R_{p} \mathrm{~s}$ of the entire pore space size distributions, compared with the PTM results. In order to provide a better understanding, we calculated the absolute relative error $R E$ of MB and PTM by $a b s\left(\left(R_{p}(\right.\right.$ method $)-R_{p}($ erosion $\left.)\right) / R_{p}($ erosion $\left.)\right)$ (Moaddel et al., 2018) and plotted $R E$ of the MB method versus that of the MB method (Fig. 16). From Fig. 16, it can be seen that errors of the PTM results were generally lower than those of the MB results.

Mercury during the MICP was forced into porous media by injection pressure. The injection pressure needs to overcome the capillary pressure of pore space, once mercury invades one smaller pore space (throat), the larger pore spaces (pores) controlled by the small pore space must also be invaded. Eventually the throat capillary pressuresaturation curve was obtained, and the pore throat radius distribution can be calculated from the curve using the Washburn (1921) equation (Njiekak et al., 2018). In order to discuss the differences in properties of throats as reflected by PTM and MICP, the pore throat radius distribution of MICP was compared to the throat radius distribution of PTM for Berea, S6 and C2 samples (Fig. 17). Since we just have 3D images of the

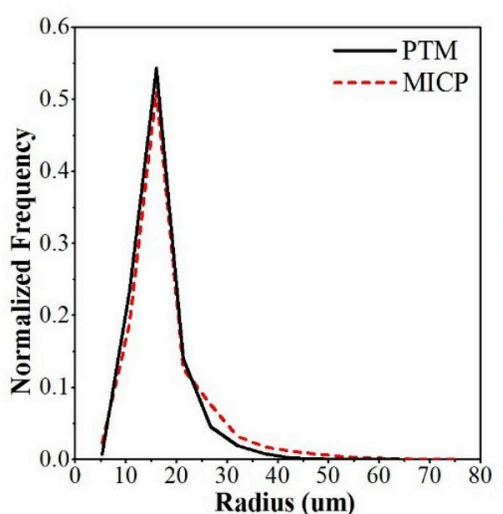

(a)

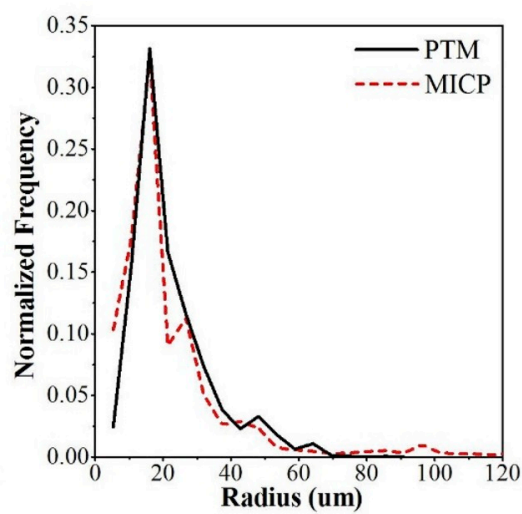

(b)

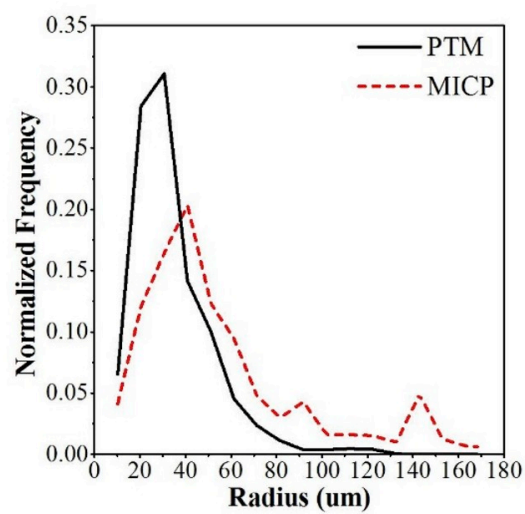

(c)

Fig. 17. Pore throat radius distribution of MICP and throat radius distribution of PTM for (a) Berea, (b) C2 and (c) S6 samples.

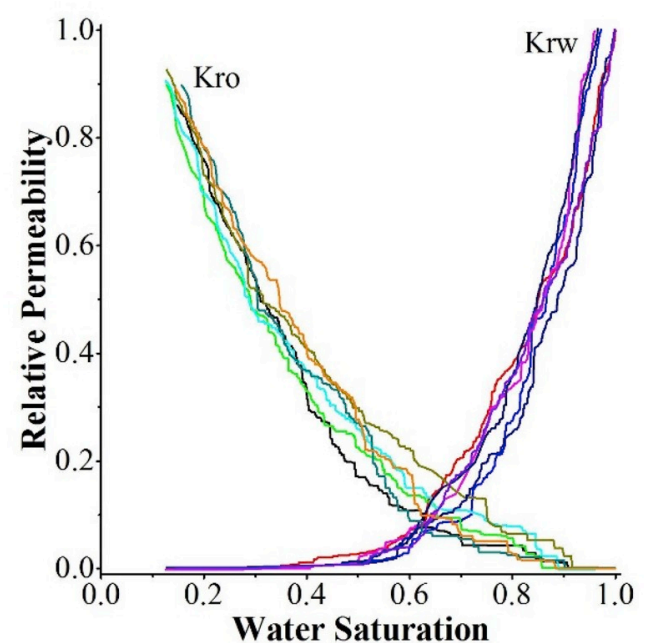

(a)

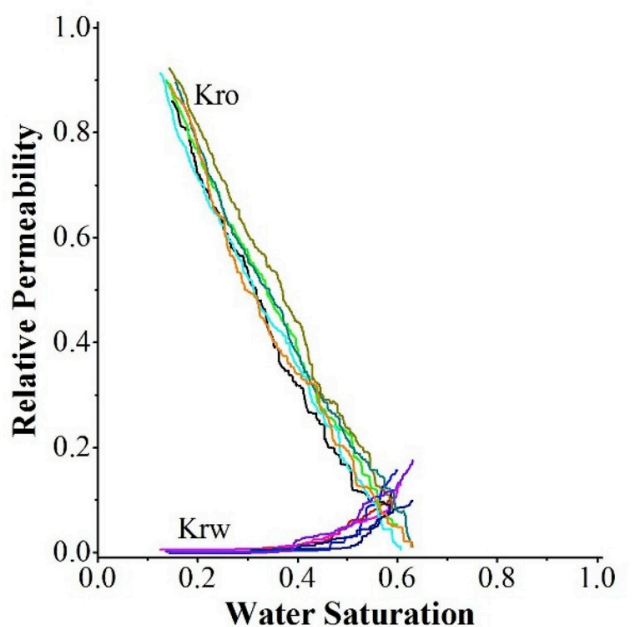

(b)

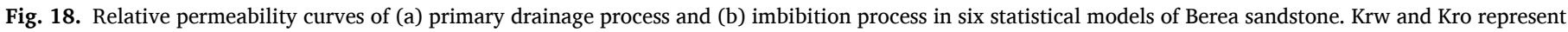
the relative permeability of water and oil, respectively. 


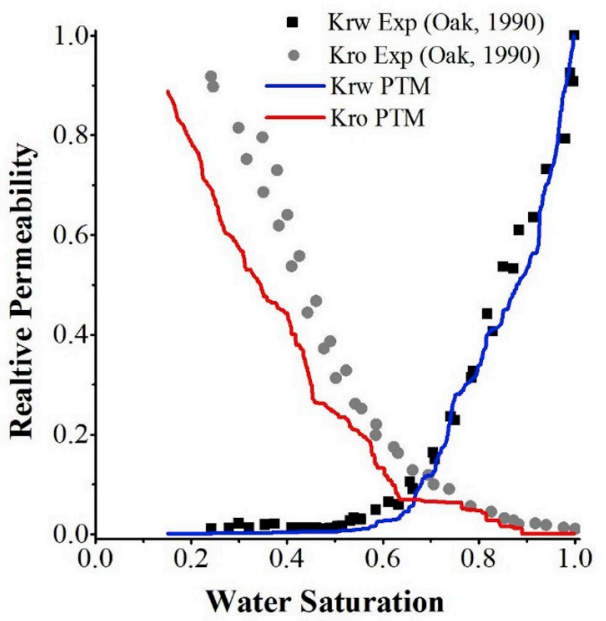

(a)

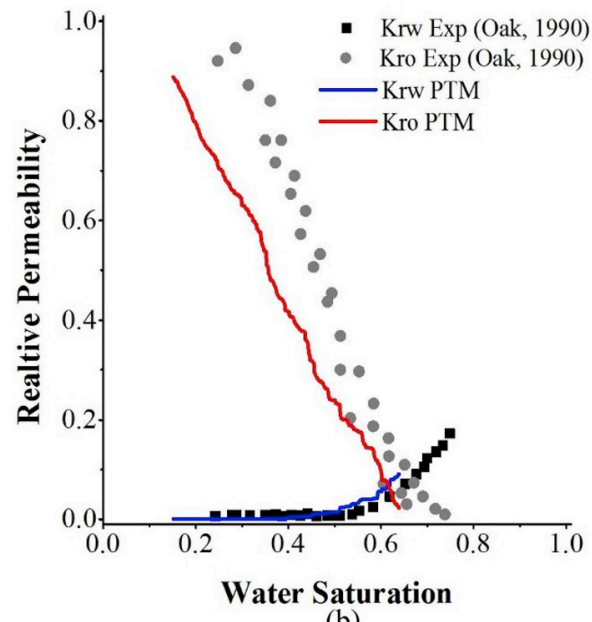

(b)

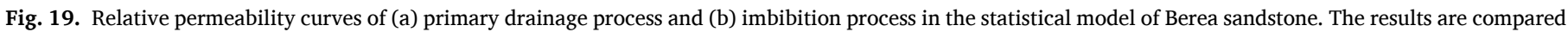
with the experimental data from the work of Oak (1990).

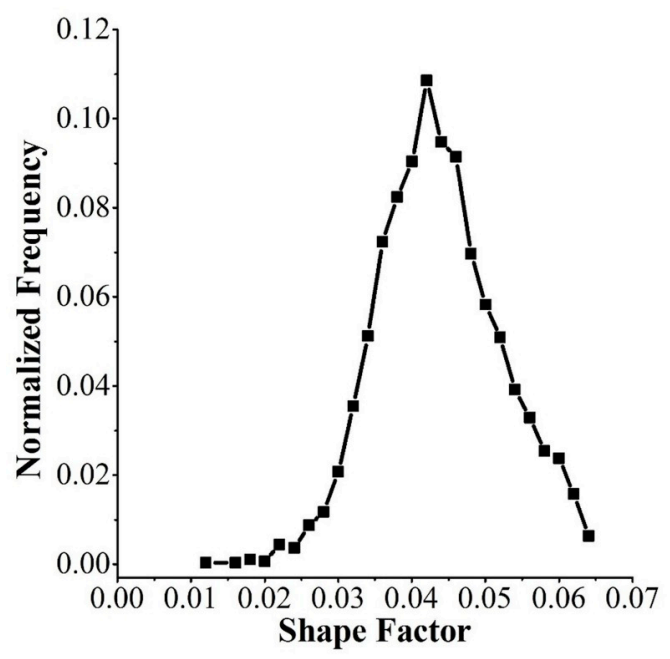

Fig. 20. Throat shape factor distribution of Berea sandstone obtained using our method.

studied samples, the pore throat radius distribution of MICP can be only obtained from the images. We have used the pore morphology method (PMM) to provide the calculation of the MICP pore throat radius distribution on 3D images (Sweijen et al., 2017).

Fig. 17 shows that the PTM distributions were in good agreement with the MICP distributions for Berea and C2 samples. However, for the S6 sandstone, the radii corresponding to peaks of MICP distribution were larger than those corresponding to peaks of the PTM distribution. The throat content fraction of MICP peaks was less than that of the PTM peaks. It indicates that the MICP pore throat distribution can well reflect throat properties for homogeneous samples, but for the nonhomogeneous samples, the MICP pore throat distribution would underestimate the content of throat with smaller radii.

\subsection{Discussion}

In addition to characterize the pore structure, the obtained geometric and topological parameters are possible to be used as the basic input data for other researches such as reservoir classification and flow mechanism (Idowu and Blunt, 2010; Wang and Sheng, 2019; Cui et al., 2019). The data used in these studies reflect the statistical characteristics of real pore structure. In order to discuss whether our results are a competent choice for these studies, we used the obtained pore structure parameters of Berea as the basic input data to establish a stochastic pore network (Idowu and Blunt, 2010). A water and oil two-phase flow was simulated in the pore network, and the simulation results were compared to the experimental data (Oak, 1990). The setup procedure of the stochastic pore network, one can refer to Idowu and Blunt (2010).

There are two schemes of the two-phase flow simulation in the statistical model: quasi-static modeling (Øren et al., 1998; Patzek, 2001; Al-Futaisi and Patzek, 2003; Valvatne and Blunt, 2004) and dynamic modeling (Al-Gharbi and Blunt, 2005; Joekar-Niasar et al., 2010). The control forces in quasi-static modeling and dynamic modeling were the capillary force and the viscous force, respectively. In the primary drainage (oil flooding) and imbibition (water flooding) processes, the competitive relationship of the two control forces can be described by the capillary number $N_{c}, N_{c}=\mu \nu / \sigma$, where $\mu$ is the viscosity of the displaced phase and $\nu$ and $\sigma$ are the fluid velocity and the interfacial tension of the phase interface, respectively. The capillary force was used the control force and the quasi-static modeling was used as the optimal scheme, if $N_{c}<<1$. Since the two-phase flow experiment for the Berea sandstone was executed by the steady state method (Oak, 1990), in which the fluid velocity was extremely low and $N_{c}<<1$, the quasi-static modeling was chosen to simulate the two-phase flow in the corresponding statistical model. The simulator we used was developed by Valvatne and Blunt (2004).

In Oak's experiment, water viscosity and oil viscosity were $1.05 \times$ $10^{-3} \mathrm{~Pa} / \mathrm{s}$ and $1.39 \times 10^{-3} \mathrm{~Pa} / \mathrm{s}$, respectively, and the interfacial tension of the water-oil phase interface was $30 \times 10^{-3} \mathrm{~N} / \mathrm{m}$. The fluid parameters, which are the same as the experimental conditions, were used as inputs into the simulator. Referring to the parameter settings of Dong and Blunt (2009), the receding contact angle was set to 0 in the primary drainage process to ensure the water-wet. The intrinsic contact angles were set to random values between 50 and 70 in order to match the experiment residual oil saturation in the imbibition process, and the advancing and receding contact angles were subsequently calculated by their relationship of Class 3 (Morrow, 1975).

Since the spatial locations of pores in the computational domain were random (Idowu and Blunt, 2010), we first discuss the effect of pore spatial distribution on the two-phase flow results. Six pore networks were established based on the pore structure parameters of the Berea sandstone, and oil-water flows were simulated in these models. Fig. 18 shows the relative permeability curves of water and oil obtained from these six simulations. It can be seen that the relative permeability curves of water and oil in all six models were consistent with each other, 
implying that the pores' spatial distribution has little effect on the two-phase flow results. This result was the basis of the following discussion.

The relative permeability curves of water and oil in the primary drainage and imbibition process were compared to the experimental data (Oak, 1990), as shown in Fig. 19. As can be seen, the water relative permeability curves are consistent with the experimental results. The oil relative permeability curves were also similar to the experimental results, although the relative permeability of oil was slightly lower than the experimental results when the water saturation was low. The possible reasons for this phenomenon include the small shape factor of throat section (Fig. 20) and the poor connectivity, which result in more snap-off and more trapping of oil by water. From Fig. 20, the dominant shape factors ranged between 0.03 and 0.06 , implying that there were mainly the triangular and square cross sections. The two-phase flow results in general were in good agreement with the experimental data. Also, there were no adjustable coefficients in the study. It can be concluded that our results are a competent choice for these studies.

\section{Conclusions}

A novel PTM method was developed to determine the comprehensive geometric and topological parameters from 3D binary images. In this method, the entire pore space was segmented into a series of space blocks of different radii via the common mathematical morphology operations. Subsequently, these space blocks were identified as pores and throats based on the proposed morphological features of pore and throat. The geometric and topological parameters of pore structure were determined from the acquired pore-throat system. After proposing the detection criteria of pore and throat, the subsequent detecting procedure is without artificial adjustable parameters, making the method convenient to use. The algorithm was designed in a parallel scheme with a high efficiency. The characteristics of pore structures and the performance of the method were assessed for various samples. The method can comprehensively describe the pore structure properties for a variety of rock samples. The PTM results were compared to the results calculated by the available methods including the MB method, the fuzzy logic method, and the PMM method. Good agreement was reached in most cases. The PTM method can produce reliable pore structure characteristics for a wide variety of rocks. Additionally, the usability of PTM results for other studies was discussed by an example about two-phase flow simulation, and the simulation results were compared to the experimental data. The PTM results can be used as the basic input data for other researches.

It can be concluded that the developed PTM method for comprehensive characterization of pore structure is efficient, accurate, convenient, and robust. In the future we will further explore how to better avoid the limitations of morphological operations and refine the PTM algorithm used for the fractured rock samples.

\section{Additional information}

Competing interests statement: the authors declare that they have no competing financial interests.

\section{Acknowledgements}

This work is supported by the National Natural Science Foundation of China (Grant No. 41690132), the Strategic Priority Research Program of the Chinese Academy of Sciences (Grant No. XDA14010304), the Major National Science and Technology Special Program of China (Grant No. 2017ZX05037-001), the National Natural Science Foundation of China (Grant No. 41574129). We are very grateful to Imperial College Consortium on Pore Scale Modeling for sharing their rock images and two-phase flow simulator.

\section{Appendix A}

The rock type, sizes, resolutions and porosity of the studied 12 rock samples are outlined in Table A1. The topological parameters and geometric parameters obtained from 12 rock images using our method are listed in Table A2.

Table A1

Basic properties of the studied rock samples (Dong and Blunt, 2009)

\begin{tabular}{lllll}
\hline Sample & Rock Type & Resolution $(u m)$ & Size (voxel) & Porosity (\%) \\
\hline Berea & SA & 5.35 & $400^{3}$ & 19.65 \\
S1 & SA & 8.68 & $300^{3}$ & 14.13 \\
S2 & SA & 4.96 & $300^{3}$ & 24.63 \\
S3 & 9.10 & $300^{3}$ & 16.86 \\
S4 & SA & 8.96 & $300^{3}$ & 17.13 \\
S5 & SA & 4.00 & $300^{3}$ & 21.13 \\
S6 & SA & 5.10 & $300^{3}$ & 23.96 \\
S7 & SA & 4.80 & $300^{3}$ & 25.05 \\
S8 & SA & 4.89 & $300^{3}$ & 33.98 \\
S9 & SA & 3.40 & $300^{3}$ & 22.17 \\
C1 & SA & 2.85 & $400^{3}$ & 23.26 \\
C2 & CA & $500^{3}$ & 16.83 \\
\hline SA & CA & 5.35 & &
\end{tabular}

SA and CA represent sandstone and carbonate, respectively.

Table A2

Geometric and topological parameters obtained using our method from the studied rock images

\begin{tabular}{|c|c|c|c|c|c|c|c|c|c|c|c|c|}
\hline Sample & Berea & S1 & $\mathrm{S} 2$ & S3 & S4 & S5 & S6 & S7 & S8 & S9 & $\mathrm{C} 1$ & $\mathrm{C} 2$ \\
\hline$N_{p}$ & 6033 & 1787 & 2273 & 6783 & 4915 & 635 & 715 & 1334 & 1643 & 591 & 3012 & 4045 \\
\hline$N_{t}$ & 10166 & 2637 & 4536 & 10097 & 7618 & 984 & 1104 & 2608 & 3655 & 796 & 3913 & 4786 \\
\hline$C N_{\text {avg }}$ & 3.37 & 2.95 & 3.99 & 2.97 & 3.09 & 3.10 & 3.07 & 3.91 & 4.45 & 2.69 & 2.59 & 2.36 \\
\hline
\end{tabular}


Table A2 (continued)

\begin{tabular}{|c|c|c|c|c|c|c|c|c|c|c|c|c|}
\hline Sample & Berea & S1 & S2 & S3 & S4 & S5 & S6 & S7 & S8 & S9 & $\mathrm{C} 1$ & $\mathrm{C} 2$ \\
\hline$E u$ & -4133 & -850 & -2263 & -3314 & -2703 & -349 & -389 & -1274 & -2012 & -205 & -901 & -741 \\
\hline$\tau$ & 1.47 & 1.49 & 1.30 & 1.75 & 1.97 & 1.38 & 1.33 & 1.28 & 1.27 & 1.39 & 1.63 & 1.96 \\
\hline$R_{p, a v g}(u m)$ & 16.40 & 33.14 & 18.35 & 19.03 & 20.37 & 19.06 & 20.67 & 19.85 & 22.85 & 18.55 & 10.17 & 15.71 \\
\hline$R_{t, a v g}(u m)$ & 10.10 & 15.84 & 10.74 & 12.66 & 12.43 & 9.65 & 12.47 & 10.63 & 11.42 & 10.73 & 6.22 & 10.56 \\
\hline$f$ & 1.18 & 1.20 & 1.19 & 1.29 & 1.29 & 1.15 & 1.17 & 1.18 & 1.19 & 1.11 & 1.20 & 1.23 \\
\hline
\end{tabular}

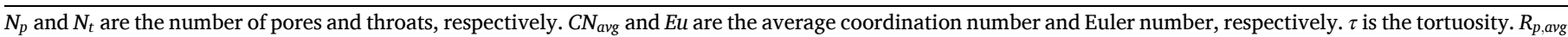
and $R_{t, a v g}$ are, respectively, the average pore radius and average throat radius. $f$ is the geometric roughness factor.

Appendix B. Supplementary data

Supplementary data to this article can be found online at https://doi.org/10.1016/j.petrol.2019.106764.

\section{References}

Al-Futaisi, A., Patzek, T.W., 2003. Impact of wettability alteration on two-phase flow characteristics of sandstones: a quasi-static description. Water Resour. Res. 39 (2), 1042. https://doi.org/10.1029/2002WR001366.

Al-Gharbi, M.S., Blunt, M.J., 2005. Dynamic network modeling of two-phase drainage in porous media. Phys. Rev. E. 71 (1), 016308 https://doi.org/10.1103/ PhysRevE.71.016308.

Al-Raoush, R.I., Madhoun, I.T., 2017. TORT3D: a MATLAB code to compute geometric tortuosity from 3D images of unconsolidated porous media. Power Technol. 320, 99-107. https://doi.org/10.1016/j.powtec.2017.06.066.

Alyafei, N., Raeini, A.Q., Paluszny, A., Blunt, M.J., 2015. A sensitivity study of the effect of image resolution on predicted petrophysical properties. Transp. Porous Media 110 (1), 157-169. https://doi.org/10.1007/s11242-015-0563-0.

An, S., Yao, J., Yang, Y., Zhang, L., Zhao, J., Gao, Y., 2016. Influence of pore structure parameters on flow characteristics based on a digital rock and the pore network model. J. Nat. Gas Sci. Eng. 31, 156-163. https://doi.org/10.1016/j. jngse.2016.03.009.

Arns, C.H., Bauget, F., Limaye, A., Sakellariou, A., Senden, T.J., Sheooard, A.P., Sok, R. M., Pinczewski, W.V., Bakke, S., Berge, L.I., Øren, P.E., 2005. Pore-scale characterization of carbonates using X-ray microtomography. SPEJ Soc. Pet. Eng. J. 10 (04), 475-484. https://doi.org/10.2118/90368-PA.

Clarkson, C.R., Solano, N., Bustin, R.M., Bustin, A.M.M., Chalmers, G.R.L., He, L., Melnichenko, Y.B., Radliński, A.P., Blach, T.P., 2013. Pore structure characterization of North American shale gas reservoirs using UASNS/SANS, gas adsorption, and mercury intrusion. Fuel 103, 606-616. https://doi.org/10.1016/j.fuel.2012.06.119.

Cui, R., Feng, Q., Chen, H., Zhang, W., Wang, S., 2019. Multiscale random pore network modeling of oil-water two-phase slip flow in shale matrix. J. Pet. Sci. Eng. 175, 46-59. https://doi.org/10.1016/j.petrol.2018.12.026.

Daigle, H., Hayman, N.W., Jiang, H., Tian, X., Jiang, C., 2017. Multiscale pore networks and their effect on deformation and transport property alteration associated with hydraulic fracturing. Energy Procedia 125, 71-79. https://doi.org/10.1016/J. EGYPRO 2017.08.067.

Dong, H., Blunt, M.J., 2009. Pore-network extraction from micro-computerizedtomography images. Phys. Rev. E. 80 (3), 036307 https://doi.org/10.1103/ PhysRevE.80.036307.

Fagbemi, S., Tahmasebi, P., Piri, M., 2018. Interaction between fluid and porous media with complex geometries: a direct pore-scale study. Water Resour. Res. https://doi. org/10.1029/2017WR022242.

Frosch, G.P., Tillich, J.E., Haselmeier, R., Holz, M., Althaus, E., 2000. Probing the pore space of geothermal reservoir sandstones by Nuclear Magnetic Resonance. Geothermics 29, 671-687. https://doi.org/10.1016/S0375-6505(00)00031-6.

Gooya, R., Bruns, S., Müter, D., Moaddel, A., Harti, R.P., Stipp, S.L.S., Sørensen, H.O., 2016. Effect of tomography resolution on the calculated microscopic properties of porous materials: comparison of sandstone and carbonate rocks. Appl. Phys. Lett. 109 (10), 104102. https://doi.org/10.1063/1.4962389.

Guo, S., 2013. Experimental study on isothermal adsorption of methane gas on three shale samples from Upper Paleozoic strata of the Ordos Basin. J. Pet. Sci. Eng. 110, 132-138. https://doi.org/10.1016/j.petrol.2013.08.048.

Henares, S., Caracciolo, L., Cultrone, G., Fernández, J., Viseras, C., 2014. The role of diagenesis and depositional facies on pore system evolution in a Triassic outcrop analogue (SE Spain). Mar. Pet. Geol. 51, 136-151. https://doi.org/10.1016/J. MARPETGEO.2013.12.004.

Hilpert, M., Miller, C.T., 2001. Pore-morphology-based simulation of drainage in totally wetting porous media. Adv. Water Resour. 24, 243-255. https://doi.org/10.1016/ S0309-1708(00)00056-7.

Hilpert, M., Glantz, R., Miller, C.T., 2003. Calibration of a pore-network model by a poremorphological analysis. Transp. Porous Media 51, 267-285. https://doi.org/ 10.1023/A:1022384431481.

Hollis, G., Vahrenkamp, V., Tull, S., Mookerjee, A., Taberner, C., Huang, Y., 2010. Pore system characterisation in heterogeneous carbonates: an alternative approach to widely-used rock-typing methodologies. Mar. Pet. Geol. 27, 772-793. https://doi. org/10.1016/j.marpetgeo.2009.12.002e.

Hu, Q., Zhang, Y., Meng, X., Zheng, L., Xie, Z., Li, M., 2017. Characterization of micronano pore networks in shale oil reservoirs of paleogene shahejie formation in dongying sag of bohai bay basin, east China. Pet. Explor. Dev. 44, 720-730. https:// doi.org/10.1016/S1876-3804(17)30083-6.
Idowu, N.A., Blunt, M.J., 2010. Pore-scale modelling of rate effects in waterflooding. Transp. Porous Media 83, 151-169. https://doi.org/10.1007/s11242-009-9468-0. Jiang, Z., Wu, K., Couples, G., Dijke, M.I.J.V., Sorbie, K.S., Ma, J., 2007. Efficient extraction of networks from three-dimensional porous media. Water Resour. Res. 43, W12S03. https://doi.org/10.1029/2006WR005780.

Jiang, W., Lin, M., Yi, Z., Li, H., Wu, S., 2017. Parameter determination using 3D FIBSEM images for development of effective model of shale gas flow in nanoscale pore clusters. Transp. Porous Media 117, 5-25. https://doi.org/10.1007/s11242-0160817-5.

Joekar-Niasar, V., Hassanizadeh, S.M., Dahle, H.K., 2010. Non-equilibrium effects in capillarity and interfacial area in two-phase flow: dynamic pore-network modelling. J. Fluid Mech. 655, 38-71. https://doi.org/10.1017/S0022112010000704.

Kus, J., 2015. Application of confocal laser-scanning microscopy (CLSM) to autofluorescent organic and mineral matter in peat, coals and siliciclastic sedimentary rocks - a qualitative approach. Int. J. Coal Geol. 137, 1-18. https://doi. org/10.1016/j.coal.2014.10.014.

Lai, J., Wang, G., Wang, Z., Chen, J., Pang, X., Wang, S., Zhou, Z., He, Z., Qin, Z., Fan, X., 2018. A review on pore structure characterization in tight sandstones. Earth Sci. Rev. 177, 436-457. https://doi.org/10.1016/j.earscirev.2017.12.003.

Langmuir, I., 1918. The adsorption of gases on plane surfaces of glass, mica and platinum. J. Am. Chem. Soc. 40 (9), 1361-1403.

Lindquist, W.B., Lee, S.M., 1996. Medial axis analysis of void structure in threedimensional images of porous media. J. Geophys. Res. 101 (B4), 8297-8310. https://doi.org/10.1029/95JB03039.

Lindquist, W.B., Venkatarangan, A., 1999. Investigating 3D geometry of porous media from high resolution images. Phys. Chem. Earth Part A. 25 (7), 593-599. https://doi. org/10.1016/S1464-1895(99)00085-x.

Mason, G., Morrow, N.R., 1991. Capillary behavior of a perfectly wetting liquid in irregular triangular tubes. J. Colloid Interface Sci. 141 (1), 262-274. https://doi. org/10.1016/0021-9797(91)90321-X.

Matheron, G., 1975. Random Sets and Integral Geometey. Wiley, New York.

Minsky, M., 1988. Memoir on inventing the confocal scanning microscope. Scanning 10, 128-138. https://doi.org/10.1002/sca.4950100403.

Moaddel, A., Müter, D., Gooya, R., Sørensen, H.O., Stipp, S.L.S., 2018. A fuzzy logic based algorithm for defining and extracting pore network structure from tomography images of rocks. Adv. Water Resour. 119, 197-209. https://doi.org/ 10.1016/j.advwatres.2018.07.011.

Morrow, N.R., 1975. The effects of surface roughness on contact angle with special reference to petroleum recovery. J. Can. Pet. Technol. 14 (4), 42-53. https://doi. org/10.2118/75-04-04.

Müter, D., Pedersen, S., Sørensen, H.O., Feidenhans'l, R., Stipp, S.L.S., 2012. Improved segmentation of X-ray tomography data from porous rock using a dual filter approach. Comput. Geosci. 49, 131-139. https://doi.org/10.1016/j. cageo.2012.06.024.

Müter, D., Sørensen, H.O., Jha, D., Harti, R., Dalby, K.N., Suhnoen, H., Feidenhans'l, R., Engstrøm, F., Stipp, S.L.S., 2014. Resolution dependence of petrophysical parameters derived from X-ray tomography of chalk. Appl. Phys. Lett. 105 (4), 043108 https:// doi.org/10.1063/1.4891965.

Njiekak, G., Schmitt, D.R., Kofman, R.S., 2018. Pore systems in carbonates formations, Weyburn field, Saskatchewan, Canada: micro-tomography, helium porosimetry and mercury intrusion porosimetry characterization. J. Pet. Sci. Eng. 171, 1496-1513. https://doi.org/10.1061/j.petrol.2018.08.029.

Okolo, G.N., Everson, R.C., Neomagus, H.W.J.P., Roberts, M.J., Sakurovs, R., 2015 Comparing the porosity and surface areas of coal as measured by gas adsorption, mercury intrusion and SAXS techniques. Fuel 141, 293-304. https://doi.org/ 10.1016/j.fuel.2014.10.046

Øren, P.E., Bakke, S., Arntzen, O.J., 1998. Extending predictive capabilities to network models. SPEJ Soc. Pet. Eng. J. 3 (04), 324-336. https://doi.org/10.2118/52052-PA.

Patzek, T.W., 2001. Verification of a complete pore network simulator of drainage and imbibition. SPEJ Soc. Pet. Eng. J. 6 (2), 144-156. https://doi.org/10.2118/71310PA.

Peng, S., Hu, Q., Dultz, S., Zhang, M., 2012. Using X-ray computed tomography in pore structure characterization for a Berea sandstone: resolution effect. J. Hydol. 472-473, 254-261. https://doi.org/10.1016/j.jhydrol.2012.09.034.

Quéré, D., 2008. Wetting and roughness. Annu. Rev. Mater. Res. 38, 71-99. https://doi. org/10.1146/annurev.matsci.38.060407.132434. 
Raeini, A.Q., Blunt, M.J., Bijeljic, B., 2014. Direct simulation of two-phase flow on microCT images of porous media and upscaling of pore-scaling forces. Adv. Water Resour. 74, 116-126. https://doi.org/10.1016/j.advwatres.2014.08.012.

Salzer, M., Thiele, S., Zengerle, R., Schmidt, V., 2014. On the importance of FIB-SEM specific segmentation algorithms for porous media. Mater. Char. 95, 36-43. https:// doi.org/10.1016/j.matchar.2014.05.014.

Sarkar, N., Chaudhuri, B.B., 1994. An efficient different box-counting approach to compute fractal dimension of image. IEEE Trans. Syst. Man Cybernet.: Systems 24 (1), 115-120. https://doi.org/10.1109/21.259692.

Serra, J., 1982. Image Analysis and Mathematical Morphology. Academic, London.

Silin, D.B., Jin, G.D., Patzerk, T.W., 2003. Robust determination of the pore-space morphology in sedimentary rocks. In: Paper Presented at SPE Annual Technical Conference and Exhibition, Soc. Of Pet. Eng. Denver, Colo.

Sweijen, T., Aslanneiad, H., Hassanizadeh, S.M., 2017. Capillary pressure-saturation relationships for porous granular materials: pore morphology method vs. pore unit assembly method. Adv. Water Resour. 107, 22-31. https://doi.org/10.1016/j. advwatres.2017.06.001.

Tahmasebi, P., Javadpour, F., Sahimi, M., 2017. Data mining and machine learning for identifying sweet spots in shale reservoirs. Expert Syst. Appl. 88, 435-447. https:// doi.org/10.1016/j.eswa.2017.07.015.

Tomutsa, L., Silin, D., Radmilovic, V., 2007. Analysis of chalk petrophysical properties by means of submicron-scale pore imaging and modeling. SPE Reserv. Eval. Eng. 10 (03), 285-293. https://doi.org/10.2118/99558-PA.

Valvatne, P.H., Blunt, M.J., 2004. Predictive pore-scale modeling of two-phase flow in mixed wet media. Water Resour. Res. 40, W07406. https://doi.org/10.1029/ 2003WR002627.

Vogel, H.J., Roth, K., 2001. Quantitative morphology and network representation of soil pore structure. Adv. Water Resour. 24, 233-242. https://doi.org/10.1016/S03091708(00)00055-5.

Wang, X., Sheng, J.J., 2019. Multi-scaled pore network modeling of gas-water flow in shale formations. J. Pet. Sci. Eng. 177, 899-908. https://doi.org/10.1016/j. petrol.2019.03.005.
Washburn, E.W., 1921. The dynamics of capillary flow. Phys. Rev. 17, 273-283.

Wenzel, R.N., 1936. Resistance of solid surfaces to wetting by water. Ind. Eng. Chem. 28 (8), 988-994. https://doi.org/10.1021/ie50320a024.

Oak, M.J., 1990. Three-phase relative permeability of water-wet Berea. In: Paper Presented at SPE/DOE Enhanced Oil Recovery Symposium. Soc. Of Pet. End (Tulsa, Okla).

Wu, Y., Tahmasebi, P., Lin, C., Zahid, M.A., Dong, C., Golab, A.N., Ren, L., 2019. A comprehensive study on geometric, topological and fractal characterizations of pore systems in low-permeability reservoirs based on SEM, MICP, NMR, and X-ray CT experiments. Mar. Pet. Geol. 103, 12-28. https://doi.org/10.1016/j. marpetgeo.2019.02.003.

Xiao, D., Lu, S., Yang, J., Zhang, Li, Li, B., 2017. Classifying multiscale pores and investing their relationship with porosity and permeability in tight sandstone gas reservoirs. Energy Fuel. 31, 9188-9200. https://doi.org/10.1021/acs. energyfuels.7b01487.

Xiong, Q., Baychev, T.G., Jivkov, A.P., 2016. Review of pore network modelling of porous media: experimental characterisations, network constructions and applications to reactive transport. J. Contam. Hydrol. 192, 101-117. https://doi. org/10.1016/J.JCONHYD.2016.07.002.

Yang, F., Hingerl, F.F., Xiao, X., Liu, Y., Wu, Z., Benson, S.M., Toney, M.F., 2015. Extraction of pore-morphology and capillary pressure curves of porous media from synchrotron-based tomography data. Sci. Rep. 5, 10635. https://doi.org/10.1038/ srep10635.

Yao, Y., Liu, D., Che, Y., Tang, D., Tang, S., Huang, W., 2010. Petrophysical characterization of coals by low-field nuclear magnetic resonance (NMR). Fuel 89, 1371-1380. https://doi.org/10.1016/j.fuel.2009.11.005.

Yi, Z., Lin, M., Jiang, W., Zhang, Z., Li, H., Gao, J., 2017. Pore network extraction from pore space images of various porous media systems. Water Resour. Res. 53 (4), 3424-3445. https://doi.org/10.1002/2016WR019272. 